Research Article

\title{
Utilization of Local Ingredients for the Production of High-Early-Strength Engineered Cementitious Composites
}

\author{
Hanwen Deng $\mathbb{1}$ \\ School of Transportation, Southeast University, Sipailou 2, Nanjing 210096, China \\ Correspondence should be addressed to Hanwen Deng; dhw0075@163.com
}

Received 18 August 2017; Accepted 25 February 2018; Published 5 April 2018

Academic Editor: Rishi Gupta

Copyright (c) 2018 Hanwen Deng. This is an open access article distributed under the Creative Commons Attribution License, which permits unrestricted use, distribution, and reproduction in any medium, provided the original work is properly cited.

\begin{abstract}
The rapid repair and retrofitting of existing transportation infrastructure requires dimensional stability and ductile repair material that can obtain sufficiently high strength in a few hours to accommodate the large loading and deformation at an early age. Engineering cementitious composites (ECCs) is a class representative of the new generation of high-performance fiber-reinforced cement-based composites (HPFRCC) with medium fiber content. The unique properties of tremendous ductility and tight multiple crack behavior indicate that ECC can be used as an effective retrofit material. The wide application of this material in China will require the use of all local ingredients. In this study, based on Chinese domestic ingredients, including matrix materials and all fibers, high-early-strength ECC (HES-ECC) was designed under the guidance of strain-hardening criterion of ECC. The matrix properties and fiber/matrix interfacial micromechanics properties were obtained from three-point-bending test and singlefiber pullout test. The mechanical properties of HES-ECC were achieved by direct tensile test. The experimental results show that HES-ECC was successfully developed by using all Chinese materials. When using the domestic PVA fiber at $2 \%$, the strength requirement can be achieved but only a low ductility. When using the domestic PE fiber at $0.8 \%$, the strength and deformation requirement both can be obtained. The HES-ECC developed in this study exhibited compressive strength of more than $25 \mathrm{MPa}$ within 6 hours, and an ultimate tensile strength of 5-6 MPa and tensile strain capacity of 3-4\% after 60 days. Moreover, the cost of using domestic fiber can be largely reduced compared with using imported fiber, up to $70 \%$; it is beneficial to the promotion of these high-early-strength ECCs in the Chinese market.
\end{abstract}

\section{Introduction}

With the rapid development of China's economy and the increasing number of transportation infrastructure, the concrete structure for repair and retrofit requires the shortest traffic interruption time. Meanwhile, the demand for highstrength or fast-hardening concrete is also increased. For example, the Road Transport Department often requires repair work to be completed within 6-8 hours in the evening to facilitate the road to be able to reopen in the early morning of the next day [1]. In the past three decades, academics and industrial scholars have done a lot of experimental research and successfully developed the repair materials which can attain enough high compressive strength and bending strength at a very early age. These concrete materials obtain early high strength by using either special fast-setting cement [2-6] or combined use of ordinary cement with accelerating agent [7-9], resulting in various strength increasing rates.

Unfortunately, the traditional concrete repairs are often lacking durability. According to conservative estimates, nearly a half of traditional concrete repair is failure [10-12]. About three-quarters of the failures are attributing to the lack of durability, and one-quarter of failure is due to structural failure. Early damage often occurs in the use of repair location because many of special cementitious materials have an unpredictable performance in different construction conditions. For instance, in many high-early-strength concrete mixtures, the freeze-thaw resistance will be decreased [4]. In addition, early cracking, accompanying autogenous 
shrinkage and rapid hydration caused by heat release under high temperature, will exacerbate the deterioration.

Engineered cementitious composite (ECC, a type of fiber-reinforced cement-based composites (FPFRCC)) is considered to be an ideal repair and retrofit material because it has a very high ductility and a tight crack width. Ductility is increasingly recognized as the most important performance in durability repair. As a repair material, ECC can exhibit excellent deformation compatibility with concrete substrate structure. The high fracture toughness and multiple cracking behaviors can make ECC effectively improve the unstable crack propagation caused by the surrounding concrete or old/new concrete interface. Therefore, it reduces the common early damage types in repair structures such as spalling and interlaminar fracture [13-15]. Unlike conventional fiber-reinforced composites, the crack width of ECC at the strain-hardening stage is an inherent characteristic itself and less than $100 \mu \mathrm{m}$. When the crack width is less than $100 \mu \mathrm{m}$, the flow rate in cracked concrete is almost 0 [16]. The permeability of water through a crack in ECC will be the lowest [17], so it can prevent the corrosion of steel in reinforced concrete. In preloaded reinforced concrete beams test under dry and wet cycles, Hiraishi et al. [17] found that the corrosion of steel was significantly eliminated while substituting ECC for concrete. Moreover, even if corrosion occurs, the strain-hardening and multiple cracking behavior of ECC will also accommodate the expansion effect caused by corrosion and prevent the occurrence of spalling. Therefore, repair and retrofit ECC can effectively extend the durablity of infrastructure $[15,18]$.

Typical ECC materials consist of cement, quartz sand, fly ash (FA) or silica fume (SF), water, super plasticizer, and chaotic short fibers. Less than or equal to $2 \%$ of the volume fraction of fibers is very favorable in terms of mixed construction and economic feasibility of the infrastructure $[15,19]$. For the large-scale application of ECCs, the use of local ingredients has become the first choice from the perspective of economic factors and the sustainability of infrastructure. The feasibility of using ECCs for the local ingredient and imported materials has been developed by a large number of researchers [20-22]. The use of domestic fiber and local ingredients in ECC has been designed and developed by Zhang and Qian [20], Ma et al. [21], and Pan et al. [22]. Zhang and Qian [20] analyzed the feasibility of ECC localization by bending test. Ma et al. [21] successfully developed a strain capacity more than $6 \%$ of domestic ECC by optimal design from fly ash and rubber particles. Pan et al. [22] studied the mechanical properties of ECC containing domestic fiber and imported fiber, respectively.

In this study, author focus on high-early-strength ECC (HES-ECC) with all local ingredients, including cement, quartz sand, silica fume, polyvinyl alcohol (PVA), fiber and polyethylene (PE) fiber. In order to get high early strength, the sulfoaluminate cement was used in this investigation. In the ECC design theory, the strain-hardening criterion of the material is determined by the fracture toughness of the matrix, the bridging capacity of fiber, and the size distribution of initial defects. Therefore, in order to obtain the domestic HES-ECC, authors measure the micromechanics parameters by single-fiber pullout test and three-point bending test, respectively. Furthermore, the mechanical properties of HES-ECC will also be tested by compression test and direct tensile test, including compressive strength, elastic modulus, ultimate tensile strength, and ultimate tensile strain.

\section{Strain-Hardening Criterion}

ECC was developed by Li of the University of Michigan in 1990s, based on the design concept of ISMD (integrated structure and material design), which is a kind of strainhardening behavior characteristics of cement-based composite with a steady crack width of $60 \mu \mathrm{m}$, meanwhile, high ductility with strain range from $1 \%$ to $4 \%$. ECC effectively linked microcut, mesoscopic material properties, and macromechanical properties. Therefore, the whole design basis of ECC is based on the multiscale link from micro to macro. Li and coworkers [23-25] proposed the ECC design theory, which was further improved by Lin et al. [26], Kanda and $\mathrm{Li}$ [27], and Yang et al. [28]. In this theory, the occurrence of steady-state flat crack propagation must meet two criteria: strength criterion and energy criterion.

2.1. Strength Criterion. In order to make ECC possess the ability of multiple cracking and high ductility, ECC should meet the strength criterion in the design process. The strength criterion stipulates that the first cracking strength $\sigma_{\mathrm{fc}}$ must be less than the bridging stress $\sigma_{0}$. That is,

$$
\sigma_{\mathrm{fc}} \leq \sigma_{0} .
$$

Based on the strength criterion, the material composition design of ECC can be modulated by adjusting the bridge stress of fiber, fracture toughness, and defect size of the matrix so as to better gain the ability of multiple cracking and high ductility performance.

2.2. Energy Criterion. The steady-state cracking of crack means that the crack width $\delta_{\text {ss }}$ and the external force $\sigma_{\text {ss }}$ are required to remain stable during the propagation of the crack. It was first proposed by Marshall and Cox [29] in the study of continuous fiber-reinforced ceramic materials. Based on the principle of fracture mechanics, they suggested that the steady-state cracking strength $\sigma_{\text {ss }}$ is calculated by using J-integral. The general solution of steady-state cracking of crack is shown in (2). Although this equation is designed only based on continuous fiber-reinforced ceramic materials, it is still applicable to other fiber-reinforced materials, including ECC:

$$
\sigma_{\mathrm{ss}} \delta_{\mathrm{ss}}-\int_{0}^{\delta_{\mathrm{ss}}} \sigma(\delta) d \delta=J_{\mathrm{tip}}
$$

where $\sigma(\delta)$ is expressed as the relationship between the fiber bridge stress $\sigma$ and the crack width $\delta$, as shown in Figure 1. $J_{\text {tip }}$ represents the crack tip toughness. In case of lower fiber content, $J_{\text {tip }}$ is determined by the matrix fracture toughness $K_{\mathrm{m}}$ and matrix Young's modulus $E_{\mathrm{m}}$, as shown in the following equation: 


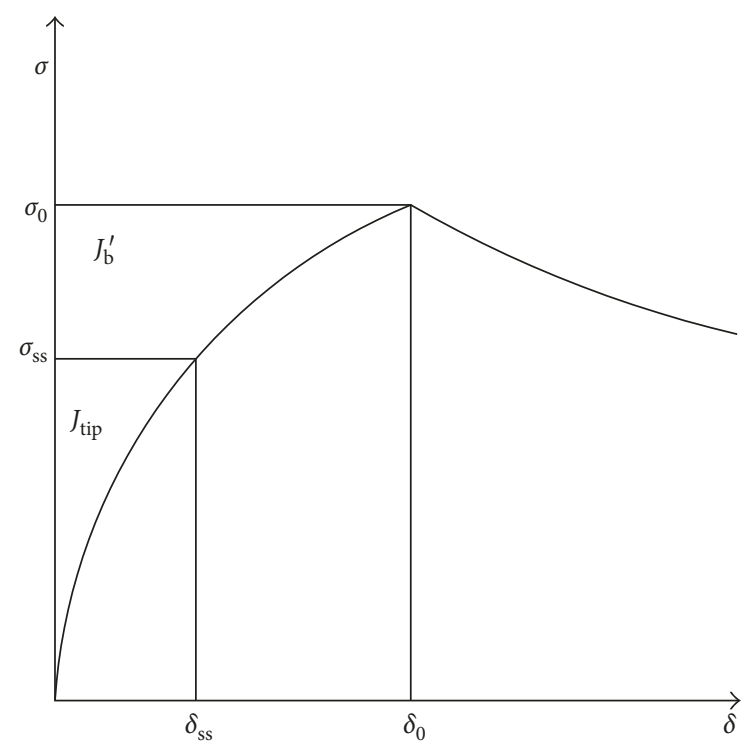

Figure 1: Typical $\sigma(\delta)$ curve for tensile strain-hardening composites.

$$
J_{\text {tip }}=\frac{K_{\mathrm{m}}^{2}}{E_{\mathrm{m}}} .
$$

Equation (2) represents the energy conservation theorem in the whole steady-state crack propagation process. $\sigma_{s s} \delta_{\text {ss }}$ is the external force acting on the crack. The crack tip width changes from 0 to $\delta_{s s}$, where the fiber bridging capability has consumed some of the energy, which is the left part of the formula. While the complementary energy is used to cause the matrix to crack at the crack tip, thereby arouse the crack to continue to develop. The fiber bridging stress will reach to a peak value $\sigma_{0}$ due to the effect of fiber, matrix, and fiber/matrix interface properties so the complementary energy also has a maximum value $J_{\mathrm{b}}^{\prime}$, as shown in Figure 1. In order to ensure that the crack can be steady-state cracking, the maximum complementary energy $J_{\mathrm{b}}^{\prime}$ must be greater than or equal to the crack tip toughness $J_{\text {tip }}$, which is the energy criterion:

$$
J_{\text {tip }} \leq \sigma_{0} \delta_{0}-\int_{0}^{\delta_{0}} \sigma(\delta) d \delta=J_{\mathrm{b}}^{\prime}
$$

According to formula (4), in order to meet energy criterion, the crack tip toughness $J_{\text {tip }}$ is limited by adjusting the mix proportion of the matrix, or the maximum complementary energy $J_{\mathrm{b}}^{\prime}$ is enhanced by designing the fiber/matrix interface parameters.

Based on the above description, in order to design the ECC materials with strain-hardening and multiple cracking behaviors, (1) and (4) should be satisfied at the same time. In addition, considering the fiber in the composites would be fractured, $\mathrm{Wu}[30]$ suggested $J_{\mathrm{b}}^{\prime} / J_{\text {tip }}>3$ and $\sigma_{0} / \sigma_{\mathrm{fc}}>1.45$ to achieve the saturated strain-hardening capacity of ECC for PVA fiber. Meanwhile, for the PE fiber, Kanda [31] indicated that the $\sigma_{0} / \sigma_{\mathrm{fc}}$ index observed from crack pattern needs to be modified, and it should be greater than 1.2 instead of 1.45 .

\section{Experiment Program}

3.1. Materials and Mixture Proportions. The raw materials used in this study were all produced by local manufacturers. The sulfoaluminate cement (SAC) [32] and silica fume [33] meet Chinese standards. The chemical compositions of SAC and SF are displayed in Table 1 . The particles size of SAC and SF is 60 to $80 \mu \mathrm{m}$ and 0.15 to $0.20 \mu \mathrm{m}$, respectively. SF does not make chemical reaction when water is added, and it, as a high activity supplementary cementitious material, will stimulate the formation of secondary hydration products. Therefore, it will enlarge the hydrated calcium silicate $(\mathrm{C}-\mathrm{S}-\mathrm{H})$ and contribute to obtain a high compressive strength [32]. The aggregates used in this study are silica sand and silica flour, which have diameters range of 106 to $212 \mu \mathrm{m}$ and 25 to $48 \mu \mathrm{m}$, respectively. Using such a small aggregate ensures uniform distribution of the fibers. Moreover, according to Ranade et al. [34], it also effectively reduces the fracture toughness of the matrix caused by crack initiation during steady-state flat crack propagation and contributes to obtain good ductility of composites. A domestic polyethylene (PE) fiber and a domestic PVA fiber (BHL, produced by Bao Hua Lin Co. Ltd. in China) were used in this study, both produced in China. As control, the imported PVA fiber (REC-15) was also investigated in this paper, produced in Japan. The physical and mechanical properties of all fibers are listed in Table 2.

According to the previously mentioned strain-hardening criterion, the strain-hardening and multiple cracking behaviors of ECC are determined by fiber, matrix, and fiber/matrix interfacial parameters. In this paper, different types of fibers will be used to research, which would result in different fiber/matrix interfacial parameters. Four ECC mixtures are listed in Table 3. ECC2, ECC3, and ECC4 have the same mix composition as the control mixture ECC1, but the imported fiber (REC-15) is directly replaced by domestic fiber. Due to rapid hardening of cement and small diameter of PE fiber, a lower PE fiber content of $0.5 \%$ and $0.8 \%$ was selected to facilitate mixing and efficient and uniform fiber distribution. The fiber content in ECC1 and ECC2 were kept at $2 \%$ by mixture volume.

All ECC materials were mixed by using a metal mixer with $10 \mathrm{~L}$ capacity. Firstly, all solid materials mixing with low speed for $1 \mathrm{~min}$, so that the mixtures were fully stirred evenly. Then, water and super plasticizer were added, continued to stir at a low speed for $1 \mathrm{~min}$, following at a high speed for another $1 \mathrm{~min}$. When the matrix slurry was homogeneous, the fibers were slowly added and sustained stirred at low speed for another 3 min until the fibers were dispersed uniformly, without agglomeration, and ECC slurry was in good fluidity. The fresh ECC was cast into molds and demolded after 2 hours, then the HES-ECC specimens were cured in a standard curing condition with $95 \pm 5 \% \mathrm{RH}$ and $20 \pm 2^{\circ} \mathrm{C}$ until testing ages.

3.2. Single-Fiber Pullout Test. To design HES-ECC, it is necessary to experimentally determine the relevant microscopic parameters. Based on the multiscale design of ECC, 
TABLE 1: Chemical composition of sulfoaluminate cement and silica fume (by weight percentage).

\begin{tabular}{lcccccccccccc}
\hline Materials & $\mathrm{CaO}$ & $\mathrm{SiO}_{2}$ & $\mathrm{Al}_{2} \mathrm{O}_{3}$ & $\mathrm{Fe}_{2} \mathrm{O}_{3}$ & $\mathrm{MgO}$ & $\mathrm{TiO}_{2}$ & $\mathrm{MnO}$ & $\mathrm{P}_{2} \mathrm{O}_{3}$ & $\mathrm{Cr}_{2} \mathrm{O}_{3}$ & $\mathrm{ZrO}_{2}$ & $\mathrm{SO}_{3}$ & $\mathrm{~K}_{2} \mathrm{O}$ \\
\hline SAC & 45.25 & 10.96 & 28.93 & 3.71 & 1.45 & 0.62 & 0.01 & 0.05 & 0.03 & 0.03 & 8.88 & 0.12 \\
SF & 1.15 & 89.02 & 1.23 & 2.63 & - & - & - & - & - & - & - & 1.32 \\
\hline
\end{tabular}

TABle 2: Physical and mechanical properties of all fibers.

\begin{tabular}{|c|c|c|c|c|c|c|c|c|}
\hline $\begin{array}{l}\text { Fiber } \\
\text { types }\end{array}$ & $\begin{array}{c}\text { Diameter, } d_{\mathrm{f}} \\
(\mu \mathrm{m})\end{array}$ & $\begin{array}{l}\text { Length, } L_{\mathrm{f}} \\
(\mathrm{mm})\end{array}$ & $\begin{array}{c}\text { Elongation } \\
(\%)\end{array}$ & $\begin{array}{l}\text { Density } \\
\left(\mathrm{g} / \mathrm{cm}^{3}\right)\end{array}$ & $\begin{array}{c}\text { Elastic modulus } \\
(\mathrm{GPa})\end{array}$ & $\begin{array}{l}\text { Tenacity } \\
(\mathrm{MPa})\end{array}$ & $\begin{array}{c}\text { Price } \\
\text { (yuan } / \mathrm{kg} \text { ) }\end{array}$ & Manufacturer \\
\hline REC-15 & 39 & 12 & 7 & 1.3 & 42.8 & 1620 & 225 & $\begin{array}{l}\text { Kuraray Co. Ltd. in } \\
\text { Japan }\end{array}$ \\
\hline BHL & 39 & 12 & 7 & 1.3 & 22 & 1250 & 80 & $\begin{array}{c}\text { Bao Hua Lin Co. Ltd. in } \\
\text { China }\end{array}$ \\
\hline $\mathrm{PE}$ & 24 & 9 & 4 & 0.97 & 116 & 2740 & 150 & $\begin{array}{l}\text { Yizheng Co. Ltd. in } \\
\text { China }\end{array}$ \\
\hline
\end{tabular}

TABLE 3: Mix design of domestic ECCs (weight ratios).

\begin{tabular}{lccccccc}
\hline Mix ID & Cement & Silica fume & Silica flour & Silica sand & Water & Super plasticizer & Fiber (by volume) \\
\hline ECC1 & 1 & 0.18 & 0.18 & 0.74 & 0.39 & 0.02 & $2 \%($ REC-15 PVA) \\
ECC2 & 1 & 0.18 & 0.18 & 0.74 & 0.39 & 0.02 & $2 \%($ BHL PVA) \\
ECC3 & 1 & 0.18 & 0.18 & 0.74 & 0.39 & 0.02 & $0.5 \%($ PE) \\
ECC4 & 1 & 0.18 & 0.18 & 0.74 & 0.39 & 0.02 & $0.8 \%($ PE) \\
\hline
\end{tabular}

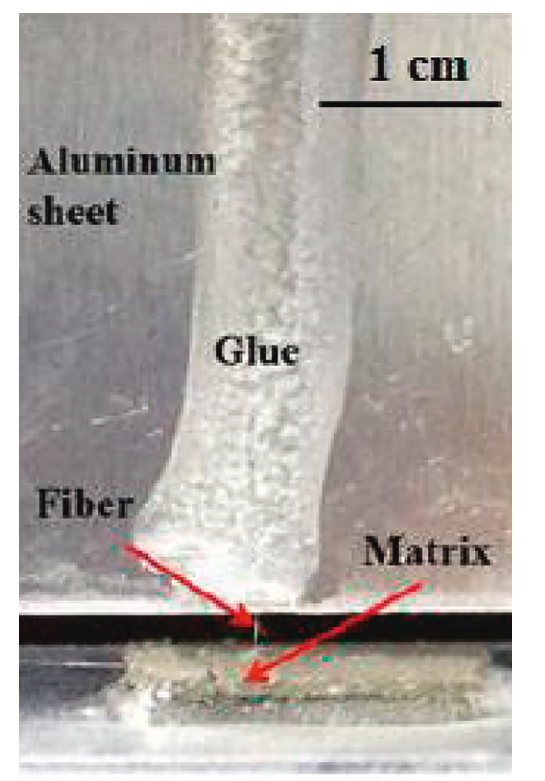

(a)

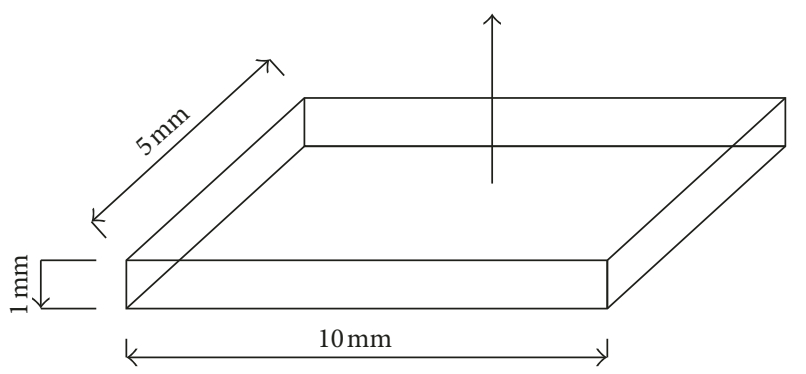

(b)

FIGURE 2: Single fiber pullout test setup: (a) the tested specimens; (b) the dimension of specimens (all dimensions in mm).

Katz and $\mathrm{Li}$ [35] suggested that the microscopic design parameters of fiber/matrix interface was measured by single fiber pullout test, including chemical bond $G_{\mathrm{d}}$, frictional bond $\tau_{0}$ and slip-hardening coefficient $\beta$. Firstly, a long continuous fiber was neatly arranged in the mold. And then pour ECC matrix slurry until it reached the specified age. The dimension of the specimen is approximately $10 \times 5 \times 1 \mathrm{~mm}^{3}$. In order to ensure that the fiber can completely draw out from matrix during pullout process, the depth of fiber is controlled at $1 \mathrm{~mm}$. The test setup is shown in Figure 2, and the displacement control was used in this test with a rate of $0.4 \mathrm{~mm} / \mathrm{min}$.

3.3. Three-Point Bending Test. In order to obtain the crack tip toughness $J_{\text {tip }}$ and the matrix fracture toughness $K_{\mathrm{m}}$, this study refers to the three-point bending test in ASTM E399 developed by the American Society for Materials and Testing [36]. The solution of the matrix fracture toughness KQ is shown in (5) and (6). The matrix of ECC is equivalent to 


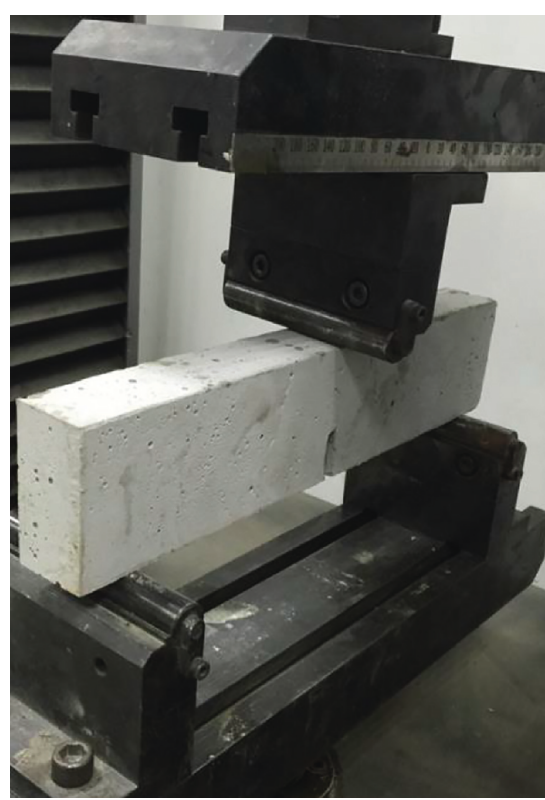

(a)

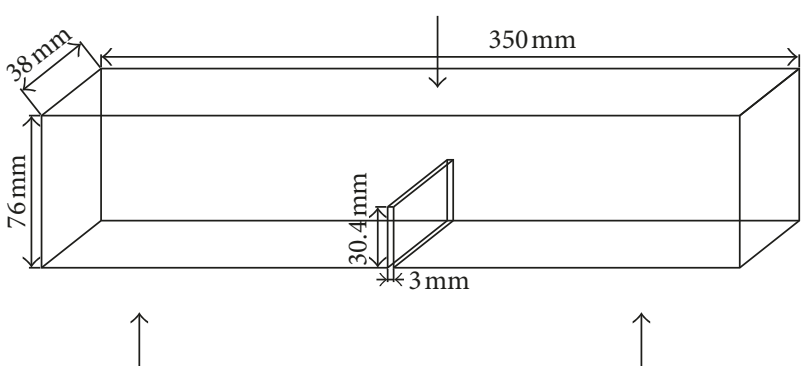

(b)

FIgURE 3: The setup of three-point bending test: (a) the tested specimens; (b) the dimension of specimens (all dimensions in mm).

cement mortar and belongs to a brittle material with linear elasticity. Therefore, this method is also suitable for measuring the fracture toughness $K_{\mathrm{m}}$ of the ECC matrix. The test setup and the specimen size are shown in Figure 3.
The dimension of tested specimen is $350 \times 76 \times 38 \mathrm{~mm}^{3}$, and the bottom of the specimen has a notch. The ratio of the notch depth to height is 0.4 . The test rate is controlled by displacement with $0.06 \mathrm{~mm} / \mathrm{min}$.

$$
\begin{aligned}
K_{\mathrm{Q}} & =\frac{P_{\mathrm{Q}} S}{\sqrt{B B_{\mathrm{N}}} W^{3 / 2}} f\left(\frac{a}{W}\right), \\
f\left(\frac{a}{W}\right) & =3 \sqrt{\frac{a}{W}} \frac{1.99-(a / W)(1-(a / W))\left[2.15-3.93(a / W)+2.7(a / W)^{2}\right]}{2(1+2(a / W))(1-(a / W))^{3 / 2}},
\end{aligned}
$$

where $K_{\mathrm{Q}}$ is the matrix fracture toughness $\left(K_{\mathrm{Q}}=K_{\mathrm{m}}\right.$, $\left.\mathrm{MPa} \cdot \mathrm{m}^{1 / 2}\right), P_{\mathrm{Q}}$ is the peak load $(\mathrm{N}), S$ is the span of support point in the specimen $(\mathrm{mm}), B$ is the thickness of the specimen $\left(B=B_{\mathrm{N}}, \mathrm{mm}\right), W$ is the width of specimens $(\mathrm{mm})$, $a$ is the notch depth $(\mathrm{mm})$, and $f(a / W)$ is the correction coefficient and the function of $(a / W)$.

3.4. Uniaxial Tensile Test. The uniaxial tensile test is based on the method recommended by the Japan Society of Civil Engineers (JSCE) for testing the properties of fiberreinforced cement-based composites (HPFRCC) [37]. The test setup and dimension of ECC specimen are shown in Figure 4. Two external linear variable displacement transducers (LVDTs), fixed on both sides of the specimen, are used to measure the deformation of the specimen during test process. The loading rate of this setup is $0.5 \mathrm{~mm} / \mathrm{min}$.

The mechanical properties of high-early-strength ECC under compressive and tensile strength are studied in this paper. All specimens will be tested at 6 hours, 24 hours, 7 days, 28 days, and 60 days, respectively. The compressive specimen size is $75 \times 75 \times 75 \mathrm{~mm}$. Due to the variable of different ECC materials, four specimens are prepared for each experiment.

\section{Results and Discussions}

4.1. Composites Compressive Strength. Figure 5 shows the results of the compressive test for HES-ECC specimens. Each of the data in Figure 5 is calculated from four compressive specimens. As shown in Figure 5, the compressive strength of the controlled ECC1 specimen was $25.4 \mathrm{MPa}$ at 6 hours. In case of ECC2, ECC3, and ECC4, these values were 23.7, 25.3, and 26.0 MPa, respectively. The compressive strength of all specimens at 6 hours can reach more than $50 \%$ that of 28 days. The compressive strength of specimens at 24 hours can gain $70 \%$ that of 28 days. These results of all compressive strength showed an increasing trend up to 60 days, including all mixtures type. The growth rate at early 


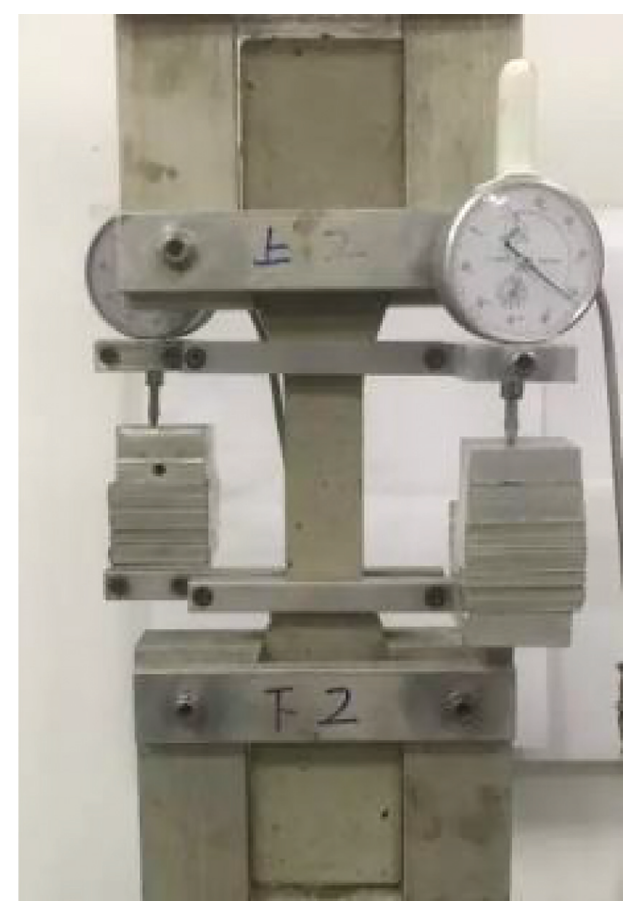

(a)

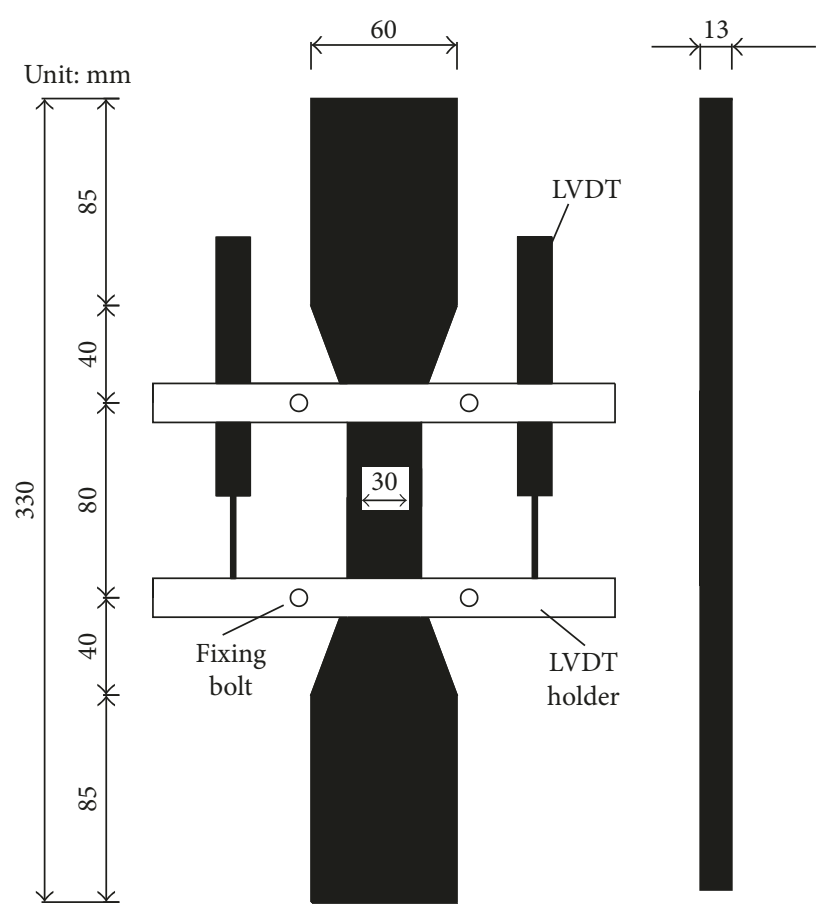

(b)

FIgURE 4: The uniaxial tensile test: (a) test setup and (b) specimen dimensions.

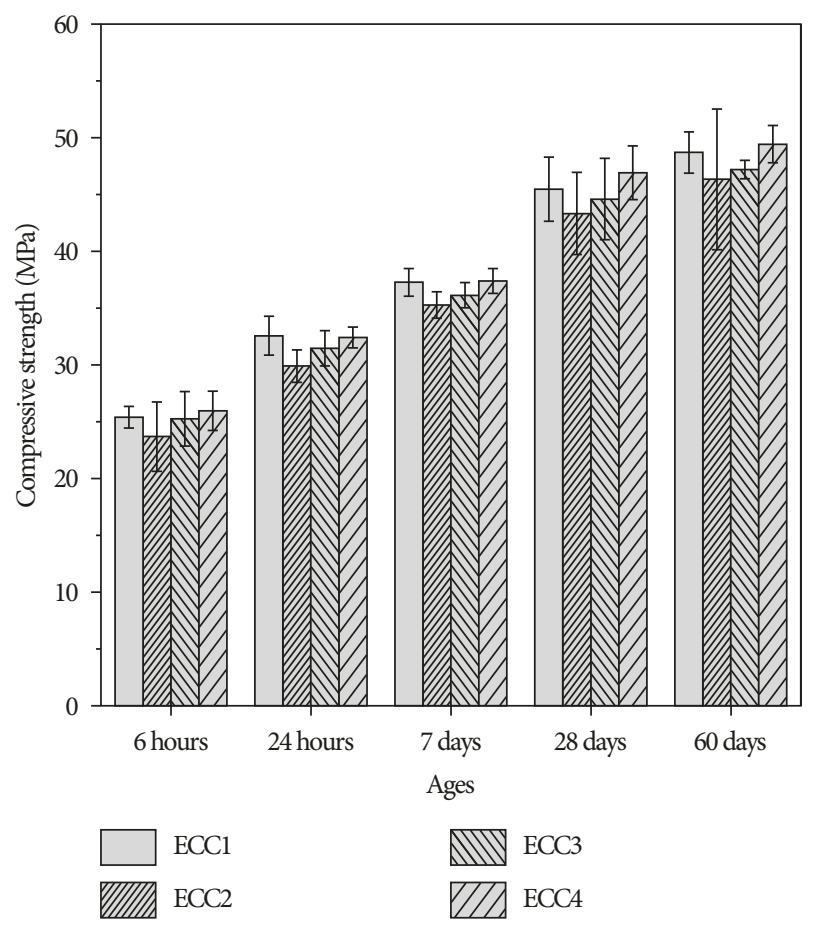

FIgUre 5: Compressive strength development of HES-ECC mixtures.

ages was faster than that of the latter ages. Compared with the controlled mixtures ECC1, the compressive strength of ECC3 and ECC4 did not change much. It indicated that the introduction of domestic PE fibers at small volume fraction has demonstrated similar effect on compressive strength at all ages. The experimental results showed that the minimum compressive strength of $20 \mathrm{MPa}$ required for the fast repair of pavement materials was satisfied by all mixture types in this study.

4.2. Control Composites Tensile Properties. As shown in Figure 6, all the curves show a significantly strain-hardening behavior. As a control mixture, the maximum ultimate tensile strain is more than $3 \%$. The first cracking strength and ultimate tensile strength of ECC1 increase with the increase of age. It is explained that as the age increases, the unhydrated cement particles in ECC1 continue to hydrate and produce more hydration products, resulting in a denser matrix and a greater matrix fracture toughness $K_{\mathrm{m}}$; the chemical bond $G_{\mathrm{d}}$ and frictional bond $\tau_{0}$ in the fiber/matrix interface were enhanced by increased hydration products, thereby resulting in the increase of the bridging stress $\sigma_{0}$.

With the increase of age, the tensile strain capacity of ECC1 has a rough decrease trend. For example, the maximum tensile strain of ECC1 is $4.13 \%$ at 6 hours, and it is reduced to $3.36 \%$ at 60 days. This is because that the increase of matrix fracture toughness $K_{\mathrm{m}}$ leads to the strengthening of the crack tip toughness $J_{\text {tip }}$. On the other hand, the complementary energy $J_{\mathrm{b}}^{\prime}$ is reduced by the change of fiber/matrix interfacial properties, resulting in the decrease of $J_{\mathrm{b}}^{\prime} / J_{\text {tip }}$.

4.3. Micromechanics-Based Design of Domestic HES-ECC. The domestic BHL fiber has no enough long available length, only REC-15 fiber and PE fiber can be applied in single-fiber pullout test to obtain related micromechanical parameters. 


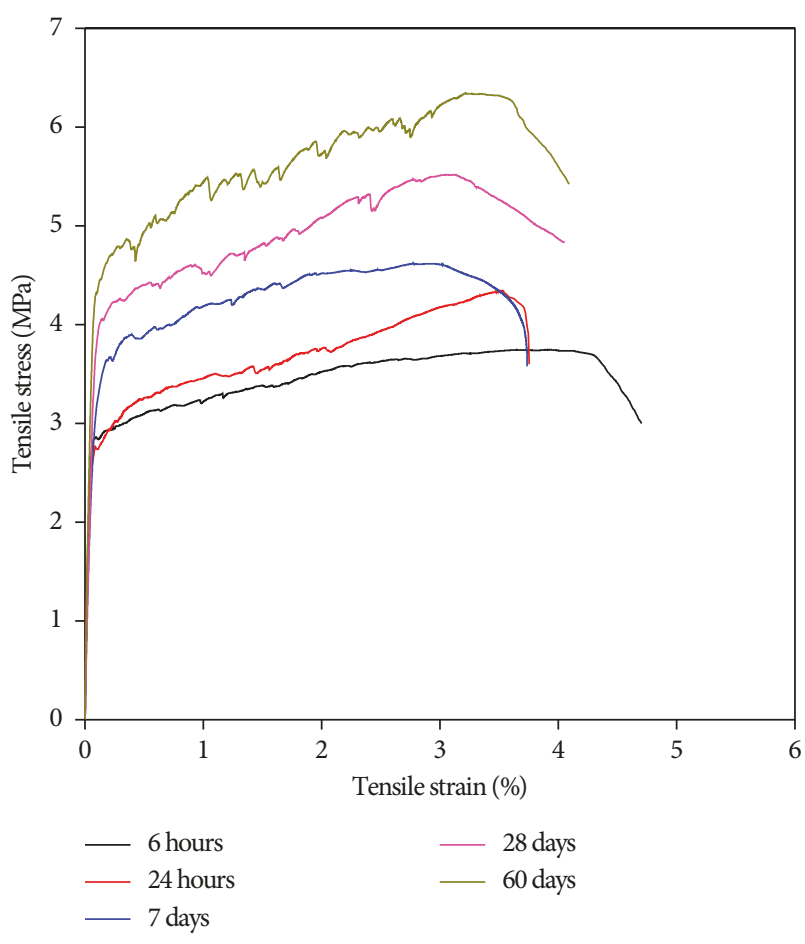

Figure 6: Tensile behaviors of the controlled mixture ECC1 with local ingredients and imported fiber (REC-15).

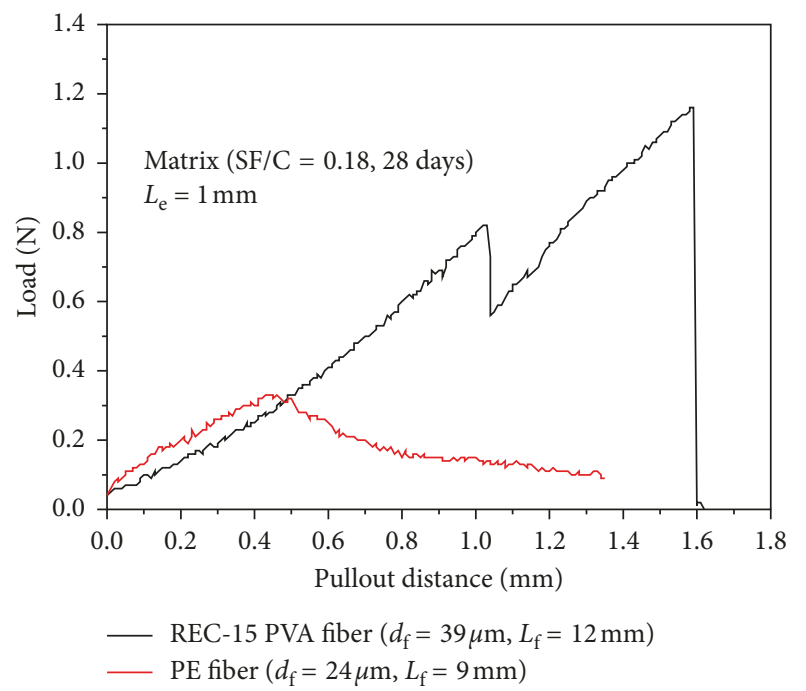

FIgURE 7: Typical pullout curve of single fiber from matrix: (a) REC-15 fiber; (b) PE fiber.

Figure 7 shows the typical pullout load-distance relationship of two different fibers from the same matrix. The microscopic mechanical parameters in the fiber/matrix interface from these figures, including chemical bond $G_{\mathrm{d}}$, frictional strength $\tau_{0}$, and slip-hardening coefficient $\beta$, both can be calculated. As shown in Figure 7(a), for PVA fiber, when fiber starts to bear the tensile force, the force value firstly rises to $P_{\mathrm{a}}$ during fiber/matrix debonding stage, and then suddenly drops to $P_{\mathrm{b}}$, indicating the chemical bond $G_{\mathrm{d}}$ in the

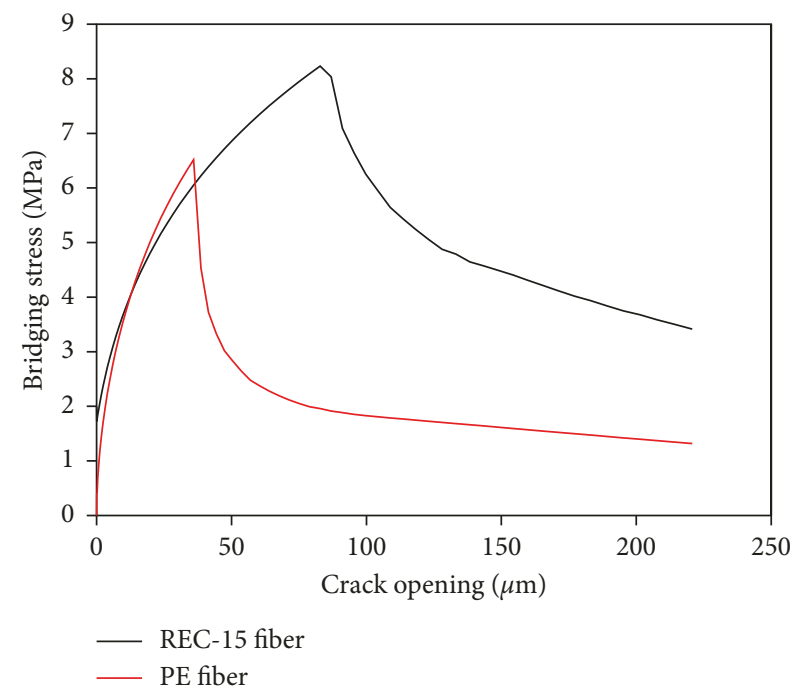

Figure 8: Computed fiber bridging stress-crack opening relationship $(\sigma-\delta)$ of ECC with REC-15 fiber and PE fiber.

fiber/matrix interface has been destroyed. After, the fiber is in a pullout stage under the action of frictional strength $\tau_{0}$ and strain-hardening capacity, the force value gradually increases to the second peak and drops until the fiber is broken. In case of fiber without chemical bond, such as PE fiber, $P_{\mathrm{a}}$ can be approximately equated with $P_{\mathrm{b}}$. When the force value reaches to only one peak $P_{\text {peak }}\left(P_{\text {peak }}=P_{\mathrm{b}}\right)$, the buried fiber end is justly debonded, and the pullout force value is provided by frictional bond strength $\tau_{0}$ (in Figure $7(b)$ ). Based on these microscopic parameters, the fiber bridging stress-crack opening displacement curve can be calculated by using MATLAB [28] (in Figure 8). The complementary energy $J_{\mathrm{b}}^{\prime}$ can also be obtained from this figure.

For the abovementioned related cases, Redon et al. [38] indicate that polymer fiber tends to reveal either sliphardening, constant friction, or slip-softening effect when pulled out from the matrix, defined as $\beta$, which can be a positive value, 0 or a negative value [39]. In this study, sliphardening coefficient $\beta$ was derived from both REC-15 fiber and PE fiber.

Li et al. [40] have proved that the load carried by the fiber was magnified in both debonding and pullout phases at nonzero inclination angles due to the snubbing effects between the inclined fiber and matrix; the snubbing coefficient $f$ was introduced to describe this behavior. In this investigation, for PVA fiber, the snubbing coefficient $f$ was defined as 0.2 according to Yang et al. [28]. The snubbing coefficient $f$ of PE fiber is computed from the peak loads of five specimens with inclined fibers. Li et al. [40] indicated that the snubbing effects can be modeled as

$$
\ln \left[\frac{P_{\text {peak }}(\phi)}{P_{\text {peak }}(0)}\right]=f \phi \text {, }
$$

where $P_{\text {peak }}(\phi)$ and $P_{\text {peak }}(0)$ are the peak force for a specimen with fiber inclination angle of $\phi$ and 0 , respectively. In the case of zero degree, the fibers are perpendicular to the crack plane. The left side of (7) was 


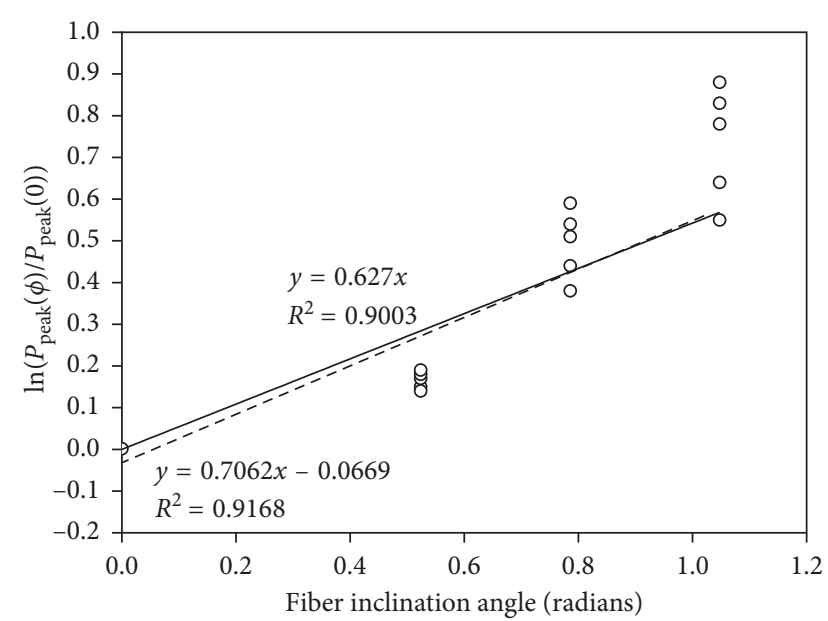

- Observed data

- - - Best fit line

- Best fit line with $y$ intercept $=0$

Figure 9: Deduction of snubbing coefficient $f$ using inclined PE fiber pullout specimens.

plotted in Figure 9 to find the best-fit curve (dashed line) through four different fiber-inclined angles. To meet the requirement of the model in (7), another best-fit curve (solid line) with zero $y$-intercept is computed. As seen in Figure 9, the considered inclination angle is $0^{\circ}, 30^{\circ}, 45^{\circ}$, and $60^{\circ}$, respectively. The snubbing coefficient $f$ of PE fiber in this study is determined as 0.63 .

Figure 10 shows the influence of curing ages on the fiber/matrix interface micromechanical parameters in ECC1 with REC- 15 fiber. The chemical bond $G_{\mathrm{d}}$, frictional strength $\tau_{0}$, and slip-hardening coefficient $\beta$ have a stable growth trend with the increase of age. This is mainly because the nonhydrated cement in ECC continues to hydrate and due to the nucleating effect of silica fume [41], making the hydration products sustain a stable growth, resulting in the increase of interfacial chemical bond $G_{d}$; on the other hand, the interfacial frictional strength $\tau_{0}$ is enhanced by the denser matrix. Figure 11 shows the influence of curing age on elastic modulus $E_{\mathrm{m}}$ and fracture toughness $K_{\mathrm{m}}$ in the matrix. As shown in Figure 11, the elastic modulus $E_{\mathrm{m}}$ and the fracture toughness $K_{\mathrm{m}}$ increase with the increase of age. It can be explained that the density of the matrix is enhanced by more hydration products, the result of combination of nonhydrated cement with the nucleating effect of silica fume, resulting in the increase of value.

Figure 12 shows the influence of curing ages on micromechanical parameters in ECC3 with PE fiber. Due to the hydrophobic nature of PE fiber, the chemical bond $G_{d}$ can be approximately equal to zero. The frictional strength $\tau_{0}$ and slip-hardening coefficient $\beta$ have also a stable increase trend with the increase of age. The larger interfacial frictional bond strength $\tau_{0}$ is generated by the densely packed ECC matrix. Due to the high strength of PE fiber, the continuous increase of the fiber bridging capacity is resisted by $\tau_{0}$.
Based on the strain-hardening criterion mentioned in Section 2, the strain-hardening performance index $\left(\sigma_{0} / \sigma_{\mathrm{fc}}\right.$, $J_{\mathrm{b}}^{\prime} / J_{\text {tip }}$ ) of ECC with different fiber is calculated and listed in Table 4. As seen in Table 4, the first cracking strength $\sigma_{\mathrm{fc}}$ is obtained from direct tensile test for the specimen without fiber. The fiber bridging stress $\sigma_{0}$ and the maximum complementary energy $J_{b}^{\prime}$ can be measured from the relationship between fiber bridging strength and crack-opening displacement curve. The crack tip toughness $J_{\text {tip }}$ was calculated by (3) using $K_{\mathrm{m}}$ and $E_{\mathrm{m}}$.

As shown in Table 4 , it can be seen that both $J_{\mathrm{b}}^{\prime} / J_{\text {tip }}$ and $\sigma_{0} / \sigma_{\mathrm{fc}}$ are larger than critical values for strain-hardening conditions in case of ECC1 and ECC3 according to $\mathrm{Wu}$ [30] and Kanda [31], which ensure that both ECC materials can develop strain-hardening behavior. Nevertheless, the corresponding values of ECC 3 are much smaller than that of ECC1 due to small fiber volume of $0.5 \%$ PE in ECC3 as opposed to 2\% PVA in ECC1. Had the mixing issue of domestic PE fiber been overcome and more PE fibers could be mixed, it is very likely that PE ECC can have a better performance index than PVA ECC. The above analysis suggests that for the utilization of local ingredients in ECC production, it is feasible to replace imported fiber with domestic PE fiber to certain extent, even though its strainhardening performance may be lower due to inability to mix $2 \%$ PE fiber in the cement matrix.

4.4. Domestic Composites Tensile Properties. Figure 13 shows the time-dependent tensile behavior of two domestic fibers. As shown in Figure 13, the significant strain-hardening behavior occurs in ECC2 and ECC3. Based on the domestic PVA fiber, the tensile strain capacity of ECC2 at all ages is less than $2 \%$, indicating the weak micromechanical parameters that occur in the domestic fiber/matrix interface. Compared with the imported fiber (seen in Figure 6), the tensile properties of ECC2 with domestic fiber is lower than ECC1 during all ages. Based on the domestic PE fiber, the ultimate tensile strain of ECC3 gradually reduced from 3.9\% at 6 hours to $3.1 \%$ at 60 days. The result from ECC 3 is consistent with the decrease in the ratio of $J_{\mathrm{b}}^{\prime} / J_{\text {tip }}$ for ECC3 as discussed before.

It can be seen from Table 4 that the fiber bridging stress $\sigma_{0}$ increases with the increase of age. The same growth trend that occurs in the ultimate tensile strength is shown in Figure 14(a). Meanwhile, the maximum tensile strength of all high-early-strength ECC at 28 days is still able to reach more than $4 \mathrm{MPa}$. In addition, ECC3 based on PE fiber materials attains a lower maximum tensile strength due to much smaller fiber volume.

Generally, the uniaxial tensile test confirmed that a reasonable tensile ductility can be achieved for ECCs with domestic fibers. The experimental data shows that the domestic ECC2 based on BHL fiber can obtain a good compressive strength and ultimate tensile strain at the same time, while a relatively lower strain capacity may limit its application. For the ECC containing 0.5\% PE fiber, it is able to provide a high ductility, but its tensile strength is somewhat sacrificed, with about $4 \mathrm{MPa}$ at 28 days. Based on the PE 


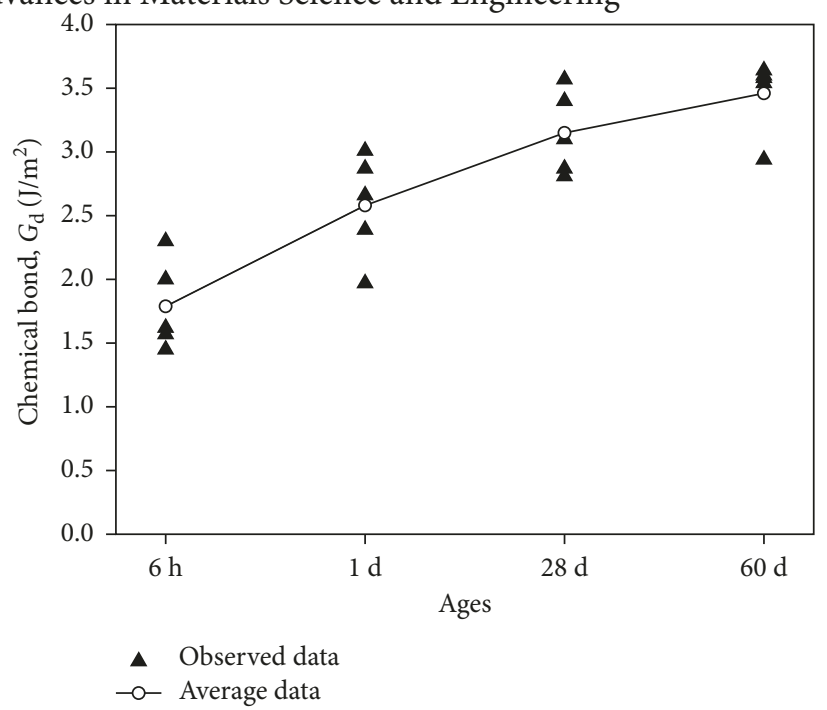

(a)

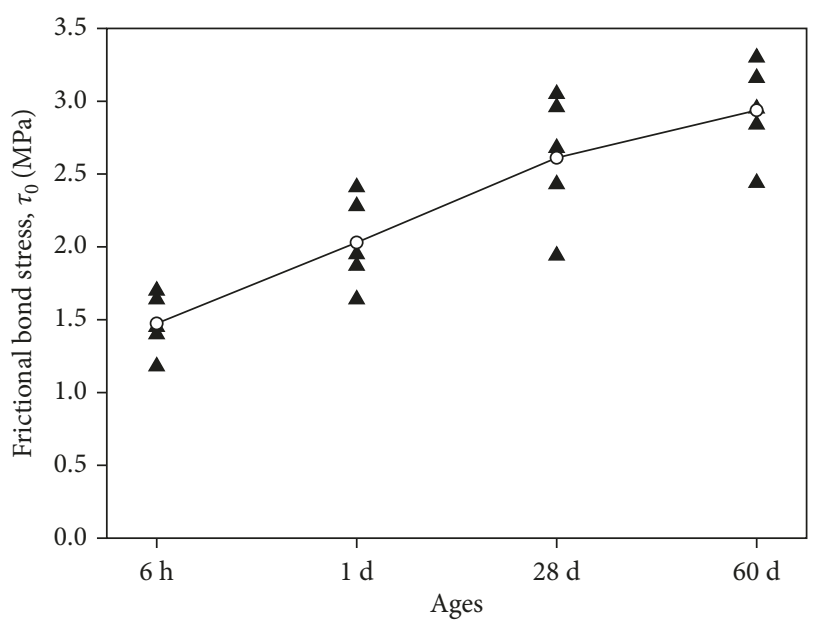

- Observed data $-\infty$ Average data

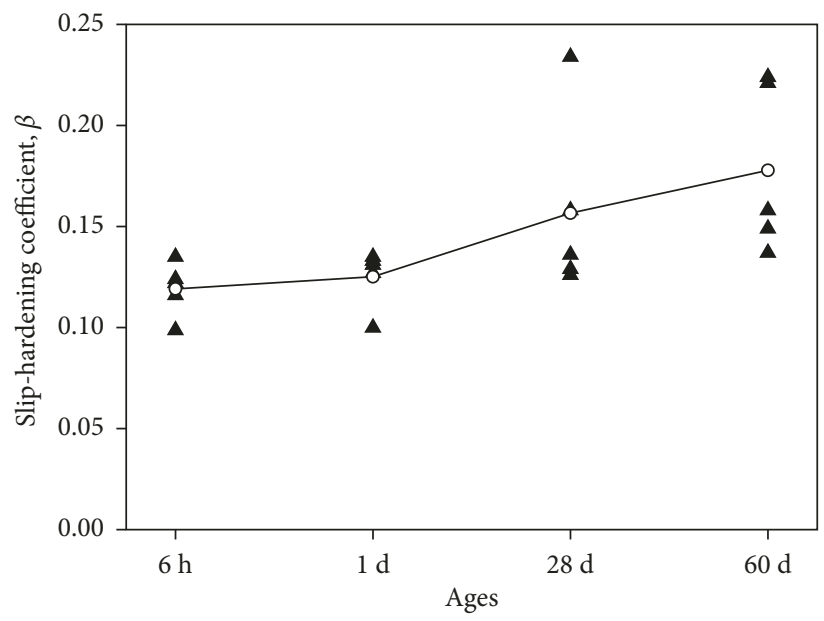

- Observed data

- - Average data

(c)

FiguRE 10: Influence of curing ages on REC-15 fiber/matrix interfacial parameters: (a) $G_{\mathrm{d}}$; (b) $\tau_{0}$; (c) $\beta$.

fiber, the domestic ECC3 cannot meet the strength requirement of engineering applications due to its low ultimate tensile strength. Therefore, the author attempts to increase the fiber volume content and overcome this defect in the next section.

4.5. Domestic HES-ECC with Different Fiber Content. As commonly known, increase in fiber volume can effectively enhance the fiber bridging ability and therefore the ultimate tensile strength. Nevertheless, it is difficult to mix $1 \% \mathrm{PE}$ fiber into the ECC matrix due to the fast setting time of sulfoaluminate cement (SAC) and smaller fiber diameter. Therefore, this study attempts to use a relatively higher fiber content $(0.8 \%$ by volume) to produce the domestic HESECC.

The performance indices $\left(\sigma_{0} / \sigma_{\mathrm{fc}}, J_{\mathrm{b}}^{\prime} / J_{\text {tip }}\right)$ of the strainhardening behavior of HES-ECCs containing PE fibers are listed in Tables 5 and 6 . The details of derivation of various parameters are the same as before. It can be seen from Tables 5 and 6 that the fiber bridging capacity $\sigma_{0}$ and complementary energy $J_{\mathrm{b}}^{\prime}$ increase significantly when the PE fiber content increases from $0.5 \%$ to $0.8 \%$ by volume, resulting in greatly improved $J_{\mathrm{b}}^{\prime} / J_{\text {tip }}$ and $\sigma_{0} / \sigma_{\mathrm{fc}}$. Theoretically, larger strain-hardening indices should lead to a better strainhardening behavior, assuming all fibers are randomly distributed.

Figures 13(b), 15, and 16 show the effect of different fiber contents on the tensile mechanical properties of ECC3 and ECC4. As shown in Figures 15 and 16(b), the domestic ECC4 exhibits an excellent high ductility. Compared with ECC3, the ultimate tensile strain of ECC4 increases by $18 \%$ at 60 days (from $3.2 \%$ to $3.8 \%$ ). Also, the maximum tensile strength of ECC4 reaches to $5.6 \mathrm{MPa}$ at 60 days, an increase of $23 \%$ compared with ECC3. Figure 16(a) shows that the maximum tensile strength is enhanced by increasing the fiber content from $0.5 \%$ to $0.8 \%$, an increase of $167 \%$ at 6 hours (from 1.5 MPa to $2.5 \mathrm{MPa}$ ). However, the compressive 


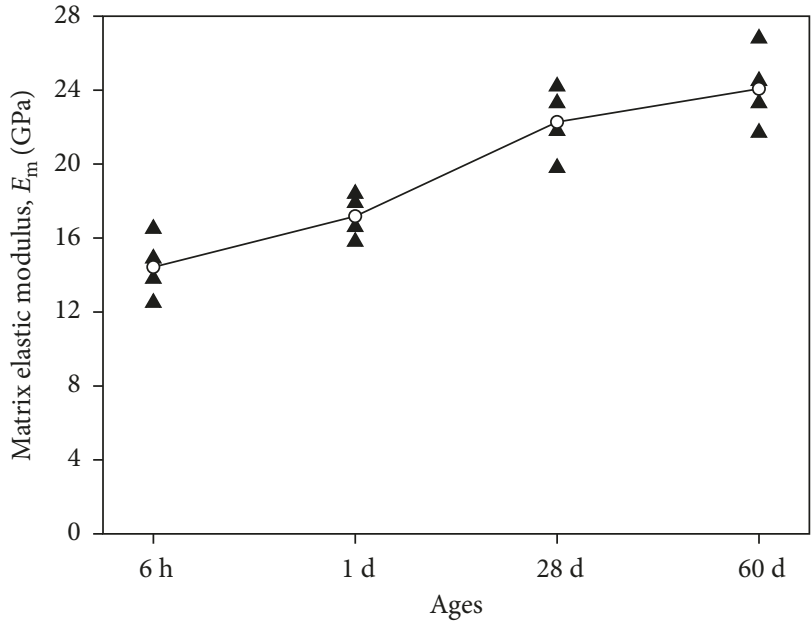

- Observed data - - Average data

(a)

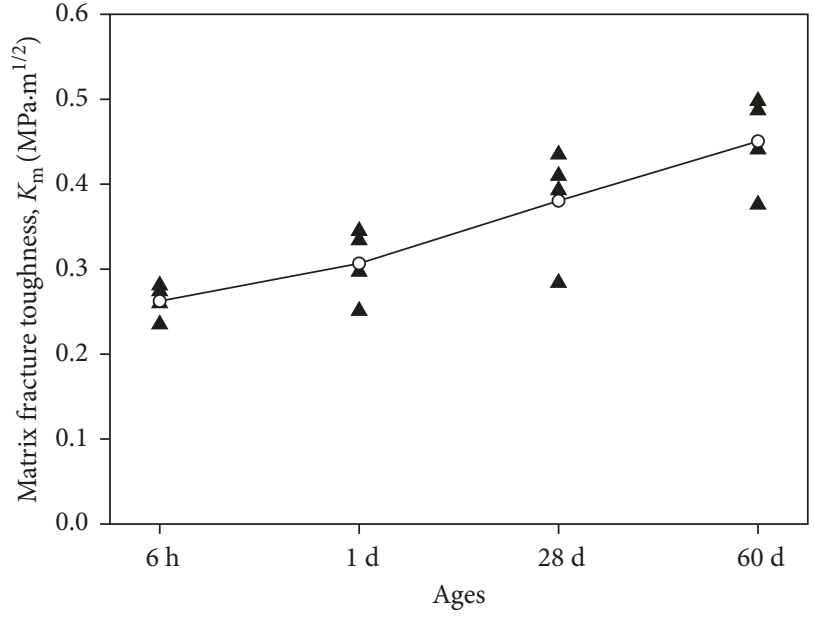

- Observed data - - Average data

Figure 11: Influence of curing ages on matrix parameters: (a) $E_{\mathrm{m}}$; (b) $K_{\mathrm{m}}$.

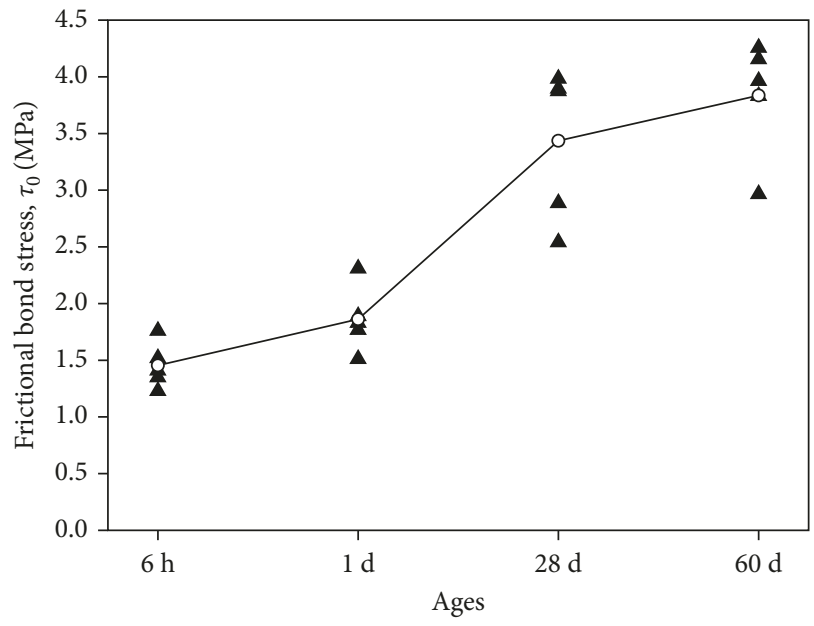

- Observed data -o- Average data

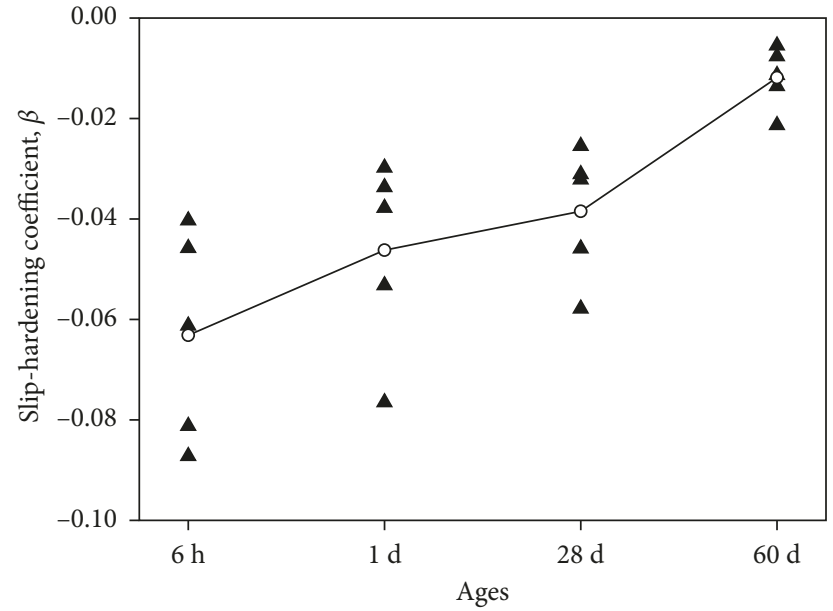

$\Delta$ Observed data - $\_$Average data

(a)

(b)

FIGURE 12: Influence of curing ages on PE fiber/matrix interfacial parameters: (a) $\tau_{0}$; (b) $\beta$.

TABLE 4: Strain-hardening performance index of HES-ECCs with different fiber.

\begin{tabular}{lccccccc}
\hline Mixture ID & Curing ages & $\sigma_{0}(\mathrm{MPa})$ & $\sigma_{\mathrm{fc}}(\mathrm{MPa})$ & $J_{\mathrm{b}}^{\prime}\left(\mathrm{J} / \mathrm{m}^{2}\right)$ & $J_{\text {tip }}\left(\mathrm{J} / \mathrm{m}^{2}\right)$ & $J_{\mathrm{b}}^{\prime} / J_{\text {tip }}$ & $\sigma_{0} / \sigma_{\mathrm{fc}}$ \\
\hline \multirow{3}{*}{ ECC1 } & $6 \mathrm{~h}$ & 6.1 & 1.9 & 193.4 & 4.9 & 39.47 \\
& $1 \mathrm{~d}$ & 7.3 & 2.3 & 179.0 & 5.6 & 3.21 \\
& $28 \mathrm{~d}$ & 8.2 & 3.2 & 183.2 & 6.6 & 27.76 \\
ECC3 & $60 \mathrm{~d}$ & 8.8 & 3.4 & 190.9 & 8.7 & 2.17 \\
& $6 \mathrm{~h}$ & 2.6 & 1.9 & 33.5 & 4.9 & 6.94 \\
& $1 \mathrm{~d}$ & 3.0 & 2.3 & 39.9 & 5.6 & 2.59 \\
& $28 \mathrm{~d}$ & 4.1 & 3.2 & 46.2 & 6.6 & 7.13 \\
\end{tabular}




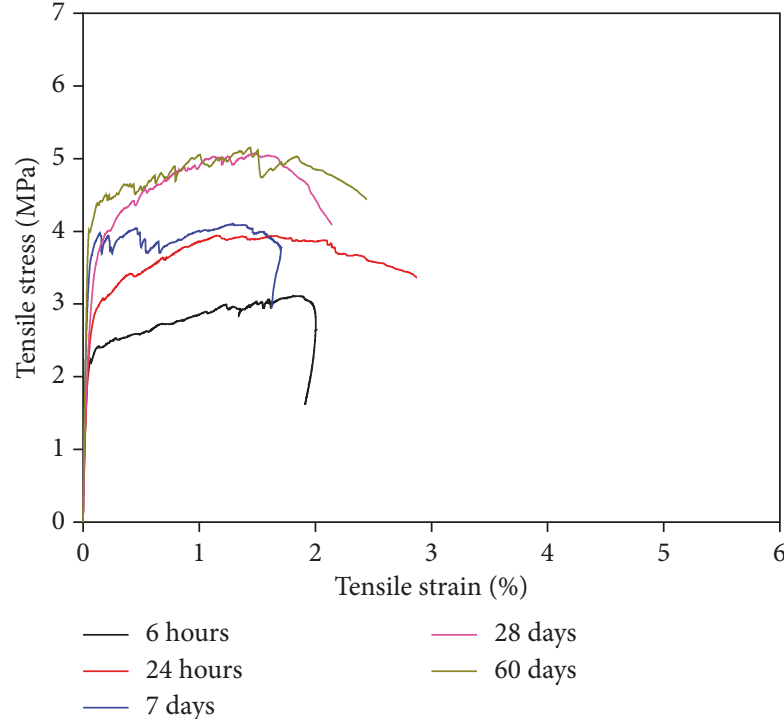

(a)

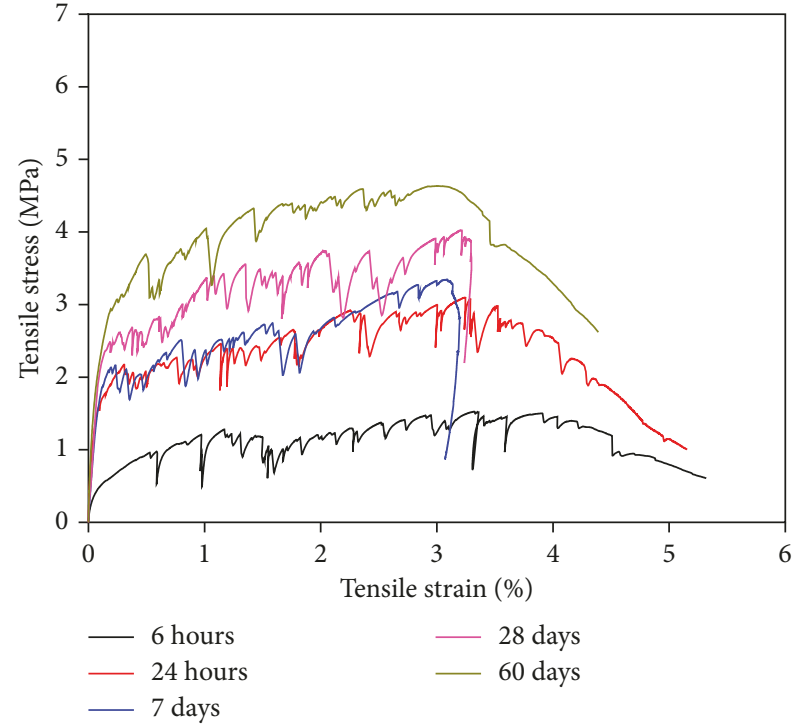

(b)

FIgURE 13: Uniaxial tensile stress-strain curves of HES-ECCs with different curing ages: (a) ECC2; (b) ECC3.

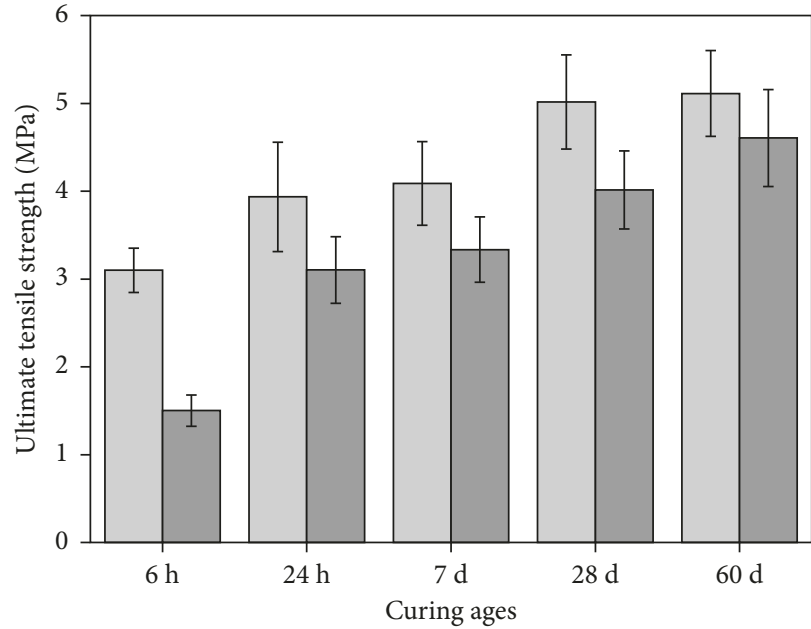

ECC2

ECC3

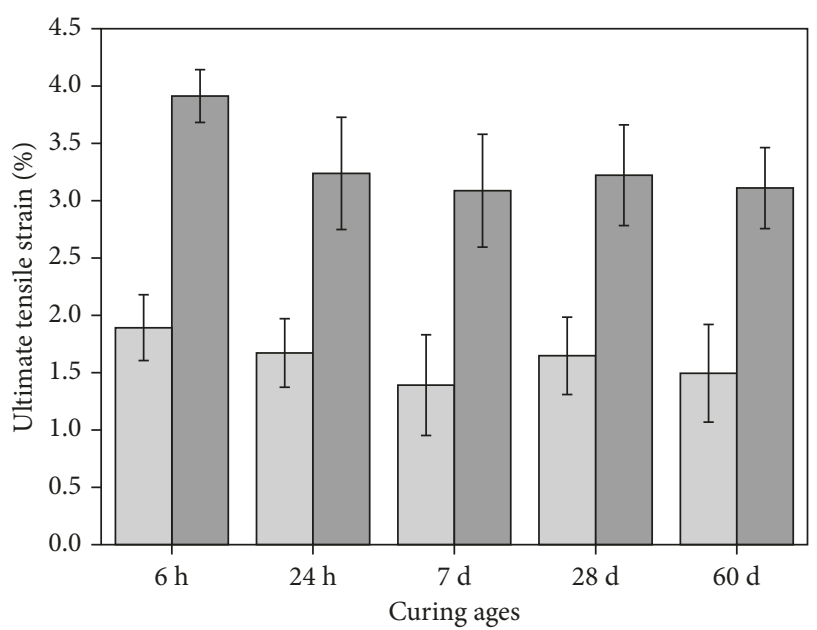

ECC2

ECC3

(a)

(b)

Figure 14: Comparison of tensile properties of HES-ECCs with different fibers at different ages: (a) ultimate tensile strength; (b) ultimate tensile strain.

TABle 5: Performance indices of strain-hardening for HES-ECCs when PE fiber content is 0.5\% (ECC3).

\begin{tabular}{lcccccc}
\hline Curing ages & $\sigma_{0}(\mathrm{MPa})$ & $\sigma_{\mathrm{fc}}(\mathrm{MPa})$ & $J_{\mathrm{b}}^{\prime}\left(\mathrm{J} / \mathrm{m}^{2}\right)$ & $J_{\text {tip }}\left(\mathrm{J} / \mathrm{m}^{2}\right)$ & $J_{\mathrm{b}}^{\prime} / J_{\text {tip }}$ & $\sigma_{0} / \sigma_{\mathrm{fc}}$ \\
\hline $6 \mathrm{~h}$ & 2.6 & 1.9 & 33.5 & 4.9 & 6.84 & 1.37 \\
$1 \mathrm{~d}$ & 3.0 & 2.3 & 39.9 & 5.6 & 7.13 & 1.30 \\
$28 \mathrm{~d}$ & 4.1 & 3.2 & 46.2 & 6.6 & 7.00 & 1.28 \\
$60 \mathrm{~d}$ & 4.2 & 3.4 & 45.2 & 8.7 & 5.20 \\
\hline
\end{tabular}

strength at 6 hours has no increase when the fiber content increases to $0.8 \%$, above $25 \mathrm{MPa}$. Therefore, the mechanical properties of ECC4 satisfy the minimum traffic compressive strength requirement.
Compared with ECC3, the first cracking strength and maximum tensile strength is enhanced by increasing the fiber content in ECC4 (seen in Figures 13(b) and 15). Meanwhile, the tensile strain capacity of ECC4 in general is 
Table 6: Performance indices of strain-hardening for HES-ECCs when PE fiber content is 0.8\% (ECC4).

\begin{tabular}{lccccc}
\hline Curing ages & $\sigma_{0}(\mathrm{MPa})$ & $\sigma_{\mathrm{fc}}(\mathrm{MPa})$ & $J_{\mathrm{b}}^{\prime}\left(\mathrm{J} / \mathrm{m}^{2}\right)$ & $J_{\text {tip }}\left(\mathrm{J} / \mathrm{m}^{2}\right)$ & $J_{\mathrm{b}}^{\prime} / J_{\text {tip }}$ \\
\hline $6 \mathrm{~h}$ & 4.2 & 1.9 & 53.5 & 4.9 & $\sigma_{0} / \sigma_{\mathrm{fc}}$ \\
$1 \mathrm{~d}$ & 4.9 & 2.3 & 64.0 & 5.6 & 2.21 \\
$28 \mathrm{~d}$ & 6.5 & 3.2 & 74.2 & 6.6 & 11.43 \\
$60 \mathrm{~d}$ & 6.7 & 3.4 & 72.6 & 8.7 & 11.24 \\
\hline
\end{tabular}

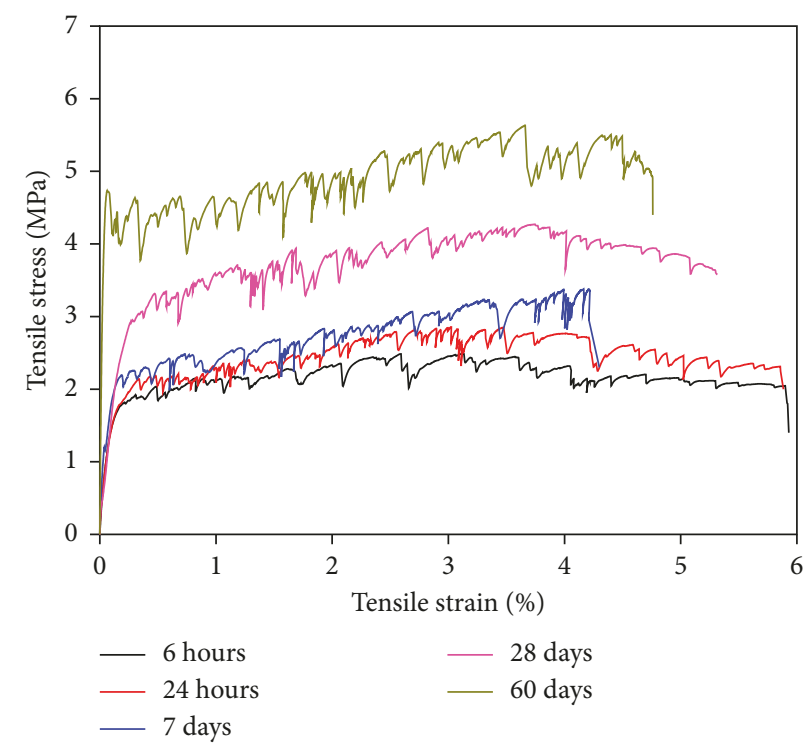

FIGURE 15: Tensile stress-strain curves of ECC4 with different curing ages.

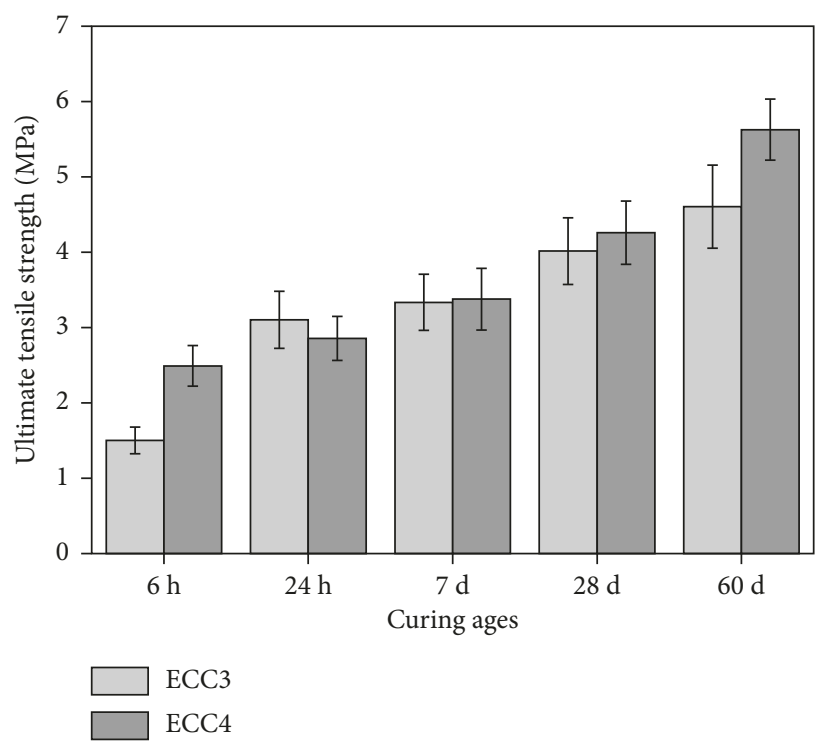

(a)

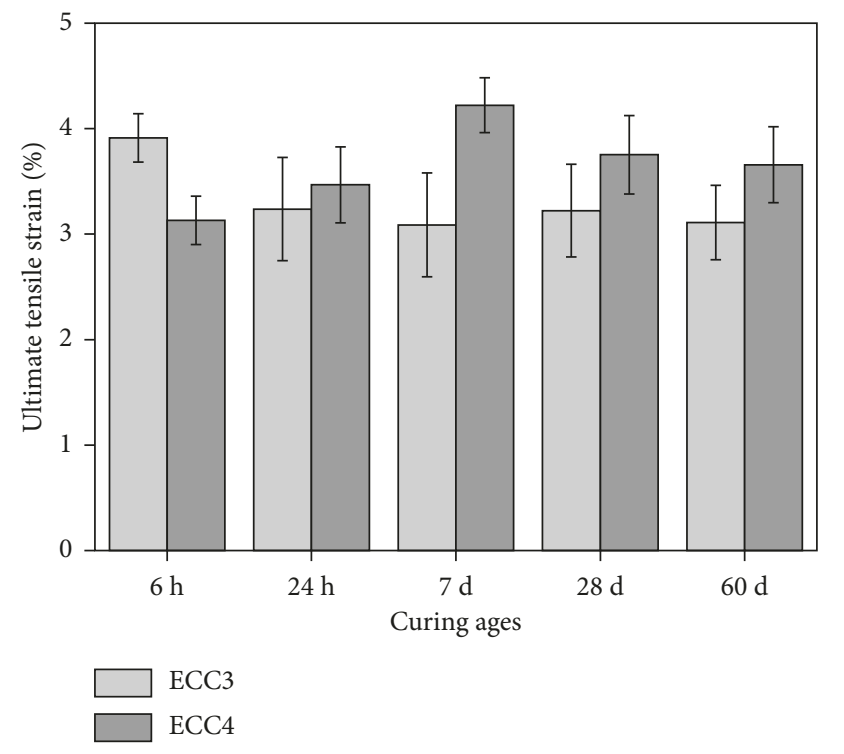

(b)

FIgURe 16: Comparison of tensile properties of PE HES-ECCs at different ages: (a) ultimate tensile strength; (b) tensile strain capacity.

better when compared with ECC3 (Figure 16(b)), which is consistent with the increase of strain-hardening performance index $J_{\mathrm{b}}^{\prime} / J_{\text {tip }}$ for ECC4.

Figure 17 shows the influence of imported fiber and domestic fiber on tensile properties of ECC1 and ECC4. As shown in Figure 17, the ultimate tensile strength of ECC4 with domestic PE fiber at all ages is less than that of controlled ECC1 with imported REC-15 fiber, approximately three-quarters of ECC1, due to a relative lower fiber content. However, the domestic ECC4 exhibits an excellent tensile 

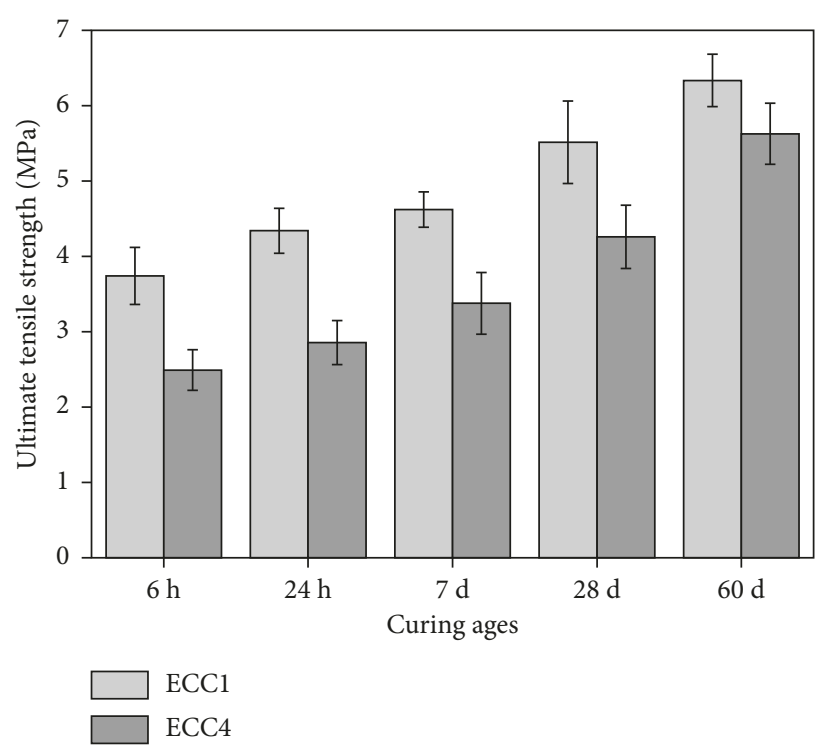

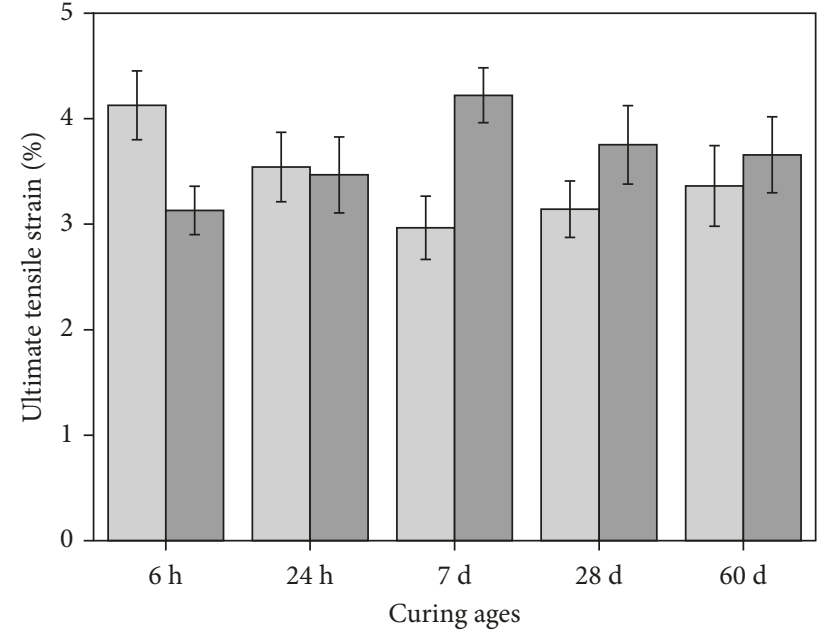

ECC1

ECC4

(a)

(b)

FIGURE 17: Comparison of tensile properties of ECC1 and ECC4 at different ages: (a) ultimate tensile strength; (b) tensile strain capacity.

strain capacity with only $0.8 \%$ fiber content. The ultimate tensile strain of ECC4 is more than that of ECC1 after 7 days with over $3 \%$, increasing by more than $120 \%$. It is indicated that $2 \%$ of imported REC- 15 fiber can be replaced by $0.8 \%$ of domestic PE fiber in the process of preparing HES-ECC.

The domestic fiber can substitute for the imported fiber due to the lower cost. The price of REC-15 fiber and PE fiber is 225 yuan $/ \mathrm{kg}$ and 150 yuan $/ \mathrm{kg}$ in China (in Table 2), respectively. For large-scale applications, for example, the production of 10,000 cubic metre HES-ECCs need the imported REC-15 fiber of $260 \mathrm{~kg}$ or the domestic PE fiber of $104 \mathrm{~kg}$, and then, the cost of imported fiber is 58,500 yuan. However, the cost of domestic fiber is only 15,600 yuan, about $27 \%$ of REC-15 fiber. Therefore, it is feasible to produce ECC materials with a lower domestic fiber, while maintaining high-early-strength and higher material ductility simultaneously.

The average crack width of ECC1, ECC2, ECC3, and ECC4 at 28 days is $61,58,55$, and $49 \mu \mathrm{m}$ respectively. The reduction of crack width after load removal can be contributed to more fiber bridging capacity from the $\mathrm{PE}$ fiber/matrix interface. It should be noted that the crack width at the very early age of 24 hours is as low as $50 \mu \mathrm{m}$ (for ECC4), whereas the tensile strain capacity is as high as $3.2 \%$. This high tensile ductility and very tight crack width at an early age of HES-ECC provide a high resistance to early-age cracking.

\section{Conclusions}

This study aims at the production of high-early-strength ECC with excellent mechanical properties using all domestic ingredients, including matrix materials and PE fiber. According to the principle of ECC micromechanics and fracture mechanics design, the interfacial micromechanical parameters were analyzed, and the high ductile ECC materials were designed and adjusted by the replacement of fiber and the increase of fiber content. The final recommendation of high-early-strength ECC is ECC4, which contains $0.8 \%$ of PE fiber by volume, meeting both strainhardening criteria (strength criterion and energy criterion). The main conclusions were as follows:

(1) To realize the localization of high-early-strength ECC, a combination of sulfoaluminate cement, silica fume, and domestic fibers is found to be helpful for attaining higher compressive strength and tensile properties at early ages. The compressive strength of more than $25 \mathrm{MPa}$ and tensile strain capacity of $1.8 \%$ within 6 hours of all high-early-strength ECCs can be obtained in this study.

(2) Using BHL fiber at $2 \%$, it was found that ultimate tensile strength of $5 \mathrm{MPa}$ and compressive strength of $40 \mathrm{MPa}$ at 28 days can be achieved, with a modest tensile strain capacity of about $2 \%$.

(3) It was found that an excellent strain-hardening behavior can be achieved when HES-ECCs use the domestic PE fiber with only $0.5 \%$ content, but with ultimate tensile strength less than $1.5 \mathrm{MPa}$ within 6 hours.

(4) When $0.8 \%$ PE fiber was used, domestic HES-ECC (ECC4) can also obtain a good tensile strain capacity of $3 \%$ and ultimate tensile strength of $2.5 \mathrm{MPa}$ within 6 hours. Meanwhile, the ultimate tensile strength of more than $5 \mathrm{MPa}$ and ultimate tensile strain of more than $3.5 \%$ after 60 days can be easily achieved. The compressive strength for this mixture exceeds $49 \mathrm{MPa}$ at 60 days.

(5) When $2 \%$ of imported REC-15 fiber was replaced by $0.8 \%$ of domestic PE fiber, the cost of all materials was significantly reduced, approximately up to $70 \%$. 


\section{Conflicts of Interest}

The author declares that there are no conflicts of interest regarding the publication of this paper.

\section{Acknowledgments}

The author would like to thank the National Natural Science Foundation of China (no. 51278097) and the Nanyang Technological University for providing a start-up grant (M4081208).

\section{References}

[1] N. J. Delatte, Concrete Pavement Design, Construction, and Performance, E \& FN Spon, New York, NY, USA, 2007.

[2] S. S. Seehra, S. Gupta, and S. Kumar, "Rapid setting magnesium phosphate cement for quick repair of concrete pavements-characterization and durability aspects," Cement and Concrete Research, vol. 23, no. 2, pp. 254-266, 1993.

[3] D. Knofel and J. F. Wang, "Properties of three newly developed quick cement," Cement and Concrete Research, vol. 24, no. 5, pp. 801-812, 1994.

[4] D. Whiting and M. Nagi, "Strength and durability if rapid highway repair concretes," Concrete International, vol. 16, no. 9, pp. 36-41, 1994.

[5] M. M. Sprinkel, Very-High-Strength Latex-modified Concrete Overlay. Report No. VTRC99-TAR3, Virginia Department of Transportation, Richmond, VA, USA, 1998.

[6] P. D. Baraguru and D. Bhatt, Rapid Hardening Concrete. Report No. FHWA NJ2001-3, New Jersey Department of Transportation, Trenton, NJ, USA, 2000.

[7] F. Parker and M. L. Shoemaker, "PCC pavement patching materials and procedures," Journal of Materials in Civil Engineering, vol. 3, no. 1, pp. 29-47, 1991.

[8] S. Kurtz, P. Balaguru, G. Consolazio, and A. Maher, Fast Track Concrete for Construction Repair. Report No. FHWA NJ2001015, New Jersey Department of Transportation, Trenton, NJ, USA, 1997.

[9] J. Anderson, J. Daczko, and J. Luciano, "Producing and evaluating Portland cement-based rapid strength concrete," Concrete International, vol. 25, no. 8, pp. 77-82, 2003.

[10] A. M. Vaysburd, C. D. Brown, B. Bissonnette, and P. H. Emmons, "Realcrete' versus 'labcrete'," Concrete International, vol. 26, no. 2, pp. 90-94, 2004.

[11] S. Wang and V. C. Li, "High early strength engineered cementitious composites," ACI Materials Journal, vol. 103, no. 2, pp. 97-105, 2006.

[12] M. Li and V. C. Li, "High-early-strength engineered cementitious composites for fast, durable concrete repairmaterial properties," ACI Materials Journal, vol. 108, no. 1, pp. 3-12, 2011.

[13] Y. M. Lim and V. C. Li, "Durable repair of aged infrastructures using trapping mechanism of engineering cementitious composites," Journal of Cement and Concrete Composites, vol. 19, no. 4, pp. 373-385, 1997.

[14] V. C. Li, H. Horii, P. Kabele, T. Kanda, and Y. M. Lim, "Repair and retrofit with engineering cementitious composites," Engineering Fracture Mechanics, vol. 65, pp. 317-334, 2000.

[15] V. C. Li, "High performance fiber reinforced cementitious composites as durable material for concrete structure repair," International Journal for Restoration of Buildings and Monuments, vol. 10, no. 2, pp. 163-180, 2004.
[16] K. Wang, D. C. Jansen, S. Shah, and A. F. Karr, "Permeability study of cracked concrete," Cement and Concrete Research, vol. 27, no. 3, pp. 381-393, 1997.

[17] Y. Hiraishi, T. Honma, M. Hakoyama, and S. Miyazato, "Steel corrosion at bending cracks in ductile fiber reinforced cementitious composites," in Proceeding of the JCI Symposium on Ductile Fiber Reinforced Cementitious Composites (DFRCC), Tokyo, Japan, 2003, in Japanese.

[18] V. C. Li and M. Lepech, "Crack resistant concrete material for transportation construction," in Proceeding of the Transportation Research Board 83rd Annual Meeting, Washington, DC, USA, January 2004.

[19] S. Wang and V. C. Li, "Polyvinyl alcohol fiber reinforced engineered cementitious composites: material design and performances," in Proceedings of International Workshop on HPFRCC in Structural Applications, pp. 23-26, Honolulu, HI, USA, 2005.

[20] Z. Zhang and S. Qian, "The feasibility of engineered cementitious composites with local compositions," in Proceedings of the 2nd International RILEM Conference on Strain Hardening Cementitious Composites, pp. 323-328, Rio de Janeiro, Brazil, December 2011.

[21] H. Ma, S. Qian, Z. Zhang, Z. Lin, and V. C. Li, "Tailoring Engineered cementitious composites with local ingredients," Construction and Building Materials, vol. 101, pp. 584-595, 2015.

[22] Z. Pan, C. Wu, J. Liu, W. Wang, and J. Liu, "Study on mechanical properties of costeffective polyvinyl alcohol engineered cementitious composites (PVA-ECC)," Construction and Building Materials, vol. 78, pp. 397-404, 2015.

[23] V. C. Li, "From micromechanics to structural engineering-the design of cementitious composites for civil engineering application," Journal of Structural Engineering/Earthquake Engineering, vol. 10, no. 2, pp. 37-48, 1993.

[24] V. C. Li and C. K. Y. Leung, "Steady state and multiple cracking of short random fiber composites," Journal of Engineering Mechanical, vol. 188, no. 11, pp. 2246-2264, 1992.

[25] V. C. Li and H. C. Wu, "Conditions for pseudo strainhardening in fiber reinforced brittle matrix composites," Applied Mechanics Reviews, vol. 45, no. 8, pp. 390-398, 1992.

[26] Z. Lin, T. Kanda, and V. C. Li, "On interface property characterization and performance of fiber reinforced cementitious composites," Concrete Science and Engineering, vol. 1, pp. 173-184, 1999.

[27] T. Kanda and V. C. Li, "Practical design criteria for saturated pseudo strain hardening behavior in ECC," Journal of Advanced Concrete Technology, vol. 4, no. 1, pp. 59-72, 2005.

[28] E. H. Yang, S. Wang, Y. Yang, and V. C. Li, "Fiber-bridging constitutive law of engineered cementitious composites," Journal of Advanced Concrete Technology, vol. 6, no. 1, pp. 181-193, 2008.

[29] D. B. Marshall and B. N. Cox, "A J-integral method for calculating steady-state matrix cracking stresses in composites," Mechanical Materials, vol. 8, pp. 127-133, 1988.

[30] C. Wu, Micromechanical Tailoring of PVA-ECC for Structural Applications in Departmental of Civil and Environmental Engineering, University of Michigan, Ann Arbor, MI, USA, 2001.

[31] T. Kanda, Design of Engineered Cementitious Composites for Ductile Seismic Resistant Elements, in Department of Civil and Environmental Engineering, University of Michigan, Ann Arbor, MI, USA, 1998. 
[32] JC/T2282-2014, Quick Setting and Rapid Hardening Sulphoaluminate Cement, China Building Materials Industry Press, Beijing, China, 2014, in Chinese.

[33] GB/T27690-2011, Silica Fume for Cement Mortar and Concrete, China Standards Press, Beijing, China, 2011, in Chinese.

[34] R. Ranade, V. C. Li, M. D. Stults, W. F. Heard, and T. S. Rushing, "Composite properties of high-strength, highductility concrete," ACI Materials Journal, vol. 110, no. 4, pp. 413-422, 2013.

[35] A. Katz and V. C. Li, "A special technique for determining the bond strength of carbon fibers in cement matrix by pullout test," Journal of Materials Science Letters, vol. 15, pp. 18211823, 1996.

[36] ASTM E399-12, Standard Test Method for Linear-Elastic Plane-Strain Fracture Toughness KIC of Metallic Materials, ASTM, West Conshohocken, PA, USA, 2012.

[37] JSCE, Recommendations for Design and Construction of High Performance Fiber Reinforced Cement Composites with Multiple Fine Cracks (HPFRCC), Japan Society of Civil Engineers, Tokyo, Japan, 2008.

[38] C. Redon, V. C. Li, C. Wu, H. Hoshiro, T. Saito, and A. Ogawa, "Measuring and modifying interface properties of PVA fibers in ECC matrix," Journal of Materials in Civil Engineering, ASCE, vol. 13, no. 6, pp. 399-406, 2001.

[39] Z. Lin and V. C. Li, "Crack bridging in fiber reinforced cementitious composites with slip-hardening interfaces," Journal of Mechanics and Physics of Solids, vol. 45, no. 5, pp. 763-787, 1997.

[40] V. C. Li, Y. Wang, and S. Backer, "Effect of inclining angle, bundling and surface treatment on synthetic fibre pullout from cement matrix," Composites Journal, vol. 20, no. 2, pp. 132-140, 1990.

[41] B. W. Langana, K. Wengb, and M. A. Warda, "Effect of silica fume and fly ash on heat of hydration of Portland cement," Cement and Concrete Research, vol. 32, pp. 1045-1451, 2002. 


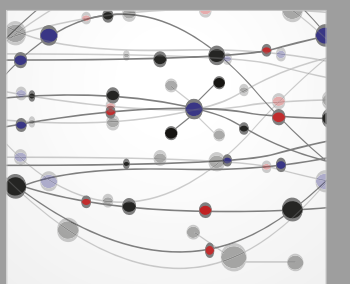

The Scientific World Journal
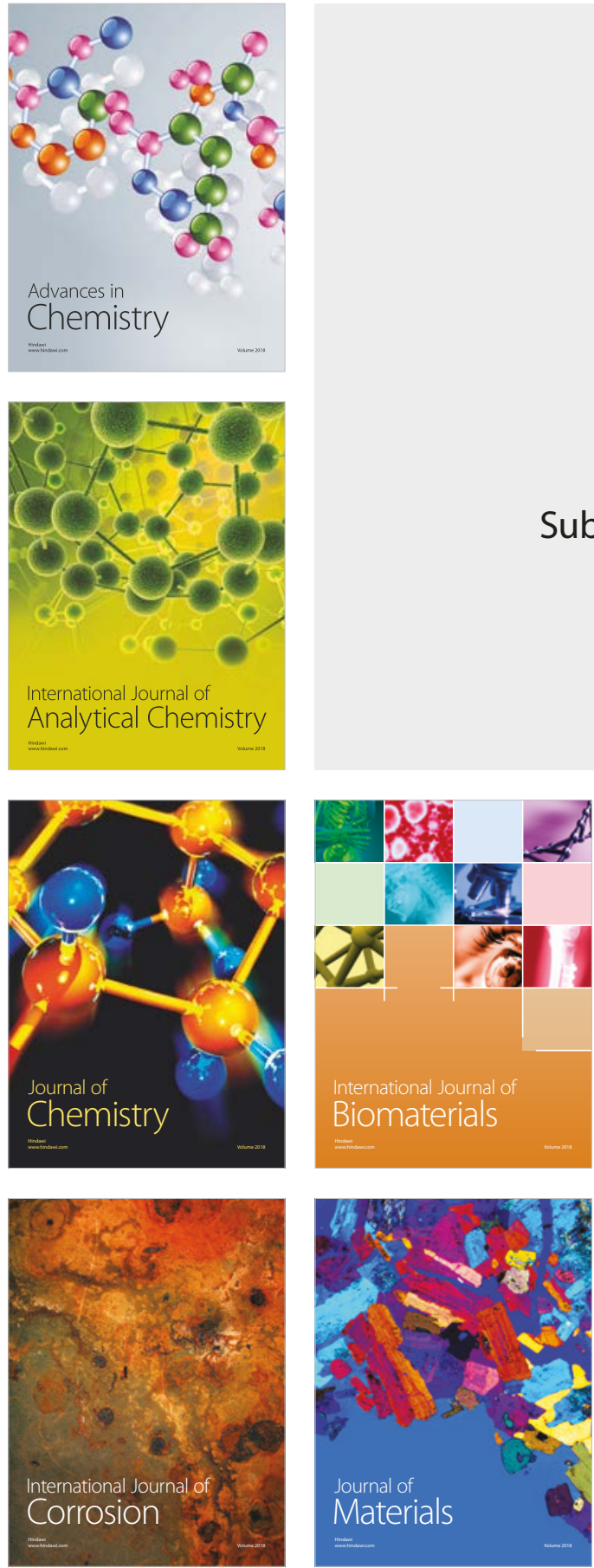

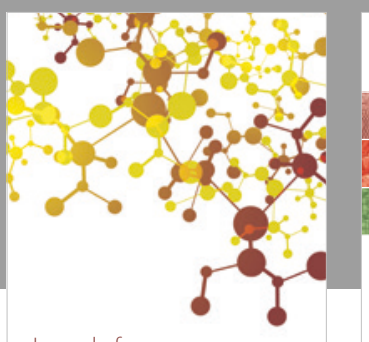

Journal of

Applied Chemistry
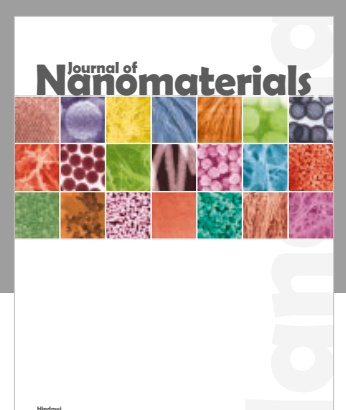

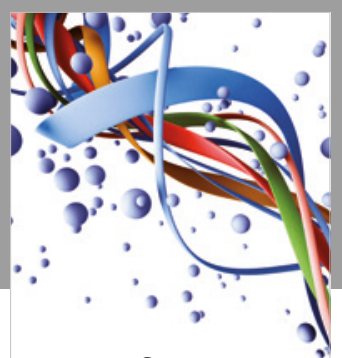

Scientifica

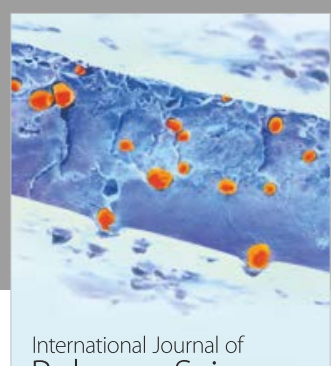

Polymer Science

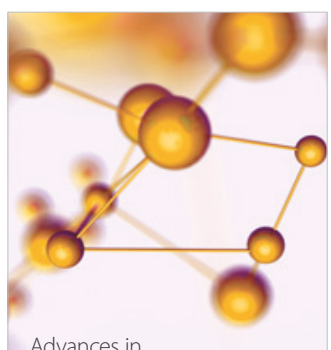

Physical Chemistry
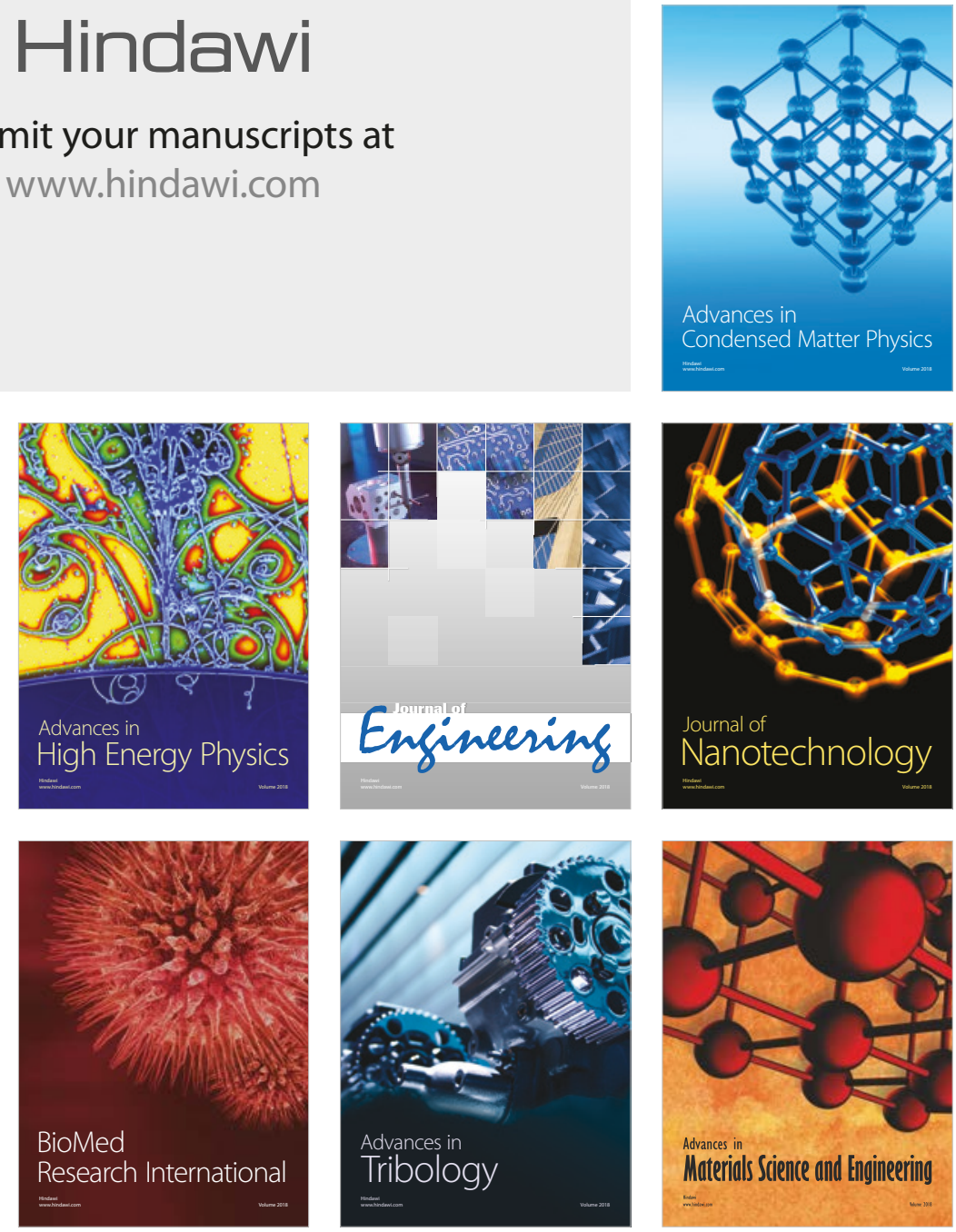